\title{
Cloud-scale ice-supersaturated regions spatially correlate with high water vapor heterogeneities
}

\author{
M. Diao ${ }^{1,2, *}$, M. A. Zondlo ${ }^{1,2}$, A. J. Heymsfield ${ }^{3}$, L. M. Avallone ${ }^{4}$, M. E. Paige ${ }^{5}$, S. P. Beaton ${ }^{6}$, T. Campos ${ }^{7}$, and \\ D. C. Rogers ${ }^{6}$ \\ ${ }^{1}$ Department of Civil and Environmental Engineering, Princeton University, New Jersey 08544, USA \\ ${ }^{2}$ Center for Mid-Infrared Technologies for Health and the Environment, Princeton University, New Jersey 08544, USA \\ ${ }^{3}$ Mesoscale and Microscale Meteorology, National Center for Atmospheric Research, Boulder, Colorado 80301, USA \\ ${ }^{4}$ Department of Atmospheric and Oceanic Sciences, University of Colorado, Colorado, USA \\ ${ }^{5}$ Southwest Sciences, Inc., Santa Fe, New Mexico 87505, USA \\ ${ }^{6}$ Earth Observing Laboratory, National Center for Atmospheric Research, Broomfield, Colorado 80021, USA \\ ${ }^{7}$ Atmospheric Chemistry Division, National Center for Atmospheric Research, Boulder, Colorado 80301, USA \\ *now at: Advanced Study Program/Earth Observing Laboratory, National Center for Atmospheric Research, Boulder, \\ Colorado 80307, USA
}

Correspondence to: M. A. Zondlo (mzondlo@ princeton.edu)

Received: 29 July 2013 - Published in Atmos. Chem. Phys. Discuss.: 27 August 2013

Revised: 9 January 2014 - Accepted: 30 January 2014 - Published: 14 March 2014

\begin{abstract}
Cirrus clouds have large yet uncertain impacts on Earth's climate. Ice supersaturation (ISS) - where the relative humidity with respect to ice (RHi) is greater than $100 \%$ - is the prerequisite condition of ice nucleation. Here we use $1 \mathrm{~Hz}(\sim 230 \mathrm{~m})$ in situ, aircraft-based observations from $87^{\circ} \mathrm{N}$ to $67^{\circ} \mathrm{S}$ to analyze the spatial characteristics of icesupersaturated regions (ISSRs). The median length of 1-D horizontal ISSR segments is found to be very small $(\sim 1 \mathrm{~km})$, which is 2 orders of magnitude smaller than previously reported. To understand the conditions of these small-scale ISSRs, we compare individual ISSRs with their horizontally adjacent subsaturated surroundings and show that $99 \%$ and $73 \%$ of the ISSRs are moister and colder, respectively. When quantifying the contributions of water vapor $\left(\mathrm{H}_{2} \mathrm{O}\right)$ and temperature $(T)$ individually, the magnitudes of the differences between the maximum RHi values inside ISSRs $\left(\mathrm{RHi}_{\max }\right)$ and the RHi in subsaturated surroundings are largely derived from the $\mathrm{H}_{2} \mathrm{O}$ spatial variabilities (by $88 \%$ ) than from those of $T$ (by $9 \%$ ). These features hold for both ISSRs with and without ice crystals present. Similar analyses for all RHi horizontal variabilities (including ISS and non-ISS) show strong contributions from $\mathrm{H}_{2} \mathrm{O}$ variabilities at various $T, \mathrm{H}_{2} \mathrm{O}$, pressure $(P)$ and various horizontal scales $(\sim 1-100 \mathrm{~km})$. Our results provide a new observational constraint on ISSRs on the
\end{abstract}

microscale $(\sim 100 \mathrm{~m})$ and point to the importance of understanding how these fine-scale features originate and impact cirrus cloud formation and the RHi field in the upper troposphere (UT).

\section{Introduction}

Cirrus clouds, located in the upper troposphere (UT) and composed of ice crystals, cover $\sim 30 \%$ of the Earth's surface (Wylie and Menzel, 1999). As a major uncertainty in climate modeling (Solomon et al., 2007), the magnitude and sign (cooling or warming) of cirrus clouds' radiative forcing are not only influenced by macroscopic properties, such as coverage, thickness and height, but also by microphysical properties, such as ice crystal number density and size distribution (Liou, 1992). In order to understand the microphysical properties of cirrus clouds, it is crucial to analyze the initial conditions of cirrus cloud formation, i.e., the conditions of ISS. For example, the frequency distribution of ISS can be used to estimate the influences of different freezing mechanisms for cirrus cloud formation (Cziczo et al., 2013), while the transition from clear-sky ISS to the ISS with ice crystals 
can help to understand the formation and evolution of ice crystal regions (Diao et al., 2013).

Ice nucleation happens once relative humidity with respect to ice $(\mathrm{RHi})$ reaches the nucleation threshold $\left(\mathrm{RHi}_{\text {nucl }}\right)$ (Koop et al., 2000; Murphy and Koop, 2005; Peter et al., 2006). By definition, $\mathrm{RHi}=e / e_{\mathrm{s}} \times 100 \%$, where $e$ is the $\mathrm{H}_{2} \mathrm{O}$ partial pressure and $e_{\mathrm{S}}$ is the saturation vapor pressure. It is crucial to understand the temporal and spatial variabilities of RHi, since they determine the time and the location of ice crystal formation, respectively. However, one of the major difficulties in understanding RHi variability is that the processes influencing it range over numerous orders of magnitude in scale, from the synoptic scale $(\sim 1000 \mathrm{~km}$; e.g., Rossby waves), mesoscale ( $\sim 100 \mathrm{~km}$; e.g., deep convection), microscale $(\sim 100 \mathrm{~m}$; e.g., small gravity waves and turbulence) to the micrometer scale (e.g., the activation of aerosols) (Kärcher and Spichtinger, 2009; Lynch et al., 2002).

Recently, Wood and Field (2011) showed that the median chord length (1-D horizontal size) of cirrus clouds is $\sim 1 \mathrm{~km}$ based on a combination of in situ aircraft observations, satellite observations and numerical model simulations. However, it is unclear how this small-scale horizontal structure of cirrus clouds forms and what factors contribute to this feature. In particular, although ISS has been widely observed in the atmosphere over various geographical locations (Gettelman et al., 2006; Heymsfield et al., 1998; Kahn et al., 2009; Krämer et al., 2009; Lamquin et al., 2012; Vömel et al., 2002), it has not been analyzed as to whether the ice-supersaturated regions (ISSRs, the regions with spatially continuous ISS) have the microscale structure similar to that of cirrus clouds, nor have the contributing factors been determined.

The spatial characteristics of ISSRs have only been analyzed on the mesoscale based on 1 min averaged $(\sim 15 \mathrm{~km}$ resolution) aircraft observations (Gierens and Spichtinger, 2000). That study concluded that the mean and median lengths of ISSR horizontal 1-D segments are $\sim 150 \mathrm{~km}$ and $\sim 50 \mathrm{~km}$, respectively, and also predicted the existence of smaller ISSRs that were not sampled. Other in situ observations at higher resolution (1 Hz), such as Krämer et al. (2009) and Ovarlez et al. (2002), analyzed the RHi distribution for the integration of all the $1 \mathrm{~Hz}$ data, but did not address how individual ISSRs are distributed in the spatial view or what factors contribute to their spatial characteristics.

To help understand the spatial characteristics of ISSRs, it is important to understand the spatial variabilities of $T$ and $\mathrm{H}_{2} \mathrm{O}$, as they directly influence the spatial variabilities of RHi. Spichtinger et al. (2003) used Microwave Limb Sounder observations on the $\sim 200 \mathrm{~km}$ scale and showed that ISSRs, on average, have colder $T$ and higher moisture than subsaturated air. However, it has not been analyzed as to how the $T$ and $\mathrm{H}_{2} \mathrm{O}$ spatial variabilities quantitatively contribute to the higher RHi values inside individual ISSRs. In addition, when deriving the general RHi spatial variability on the microscale, it is unknown whether $\mathrm{H}_{2} \mathrm{O}$ and $T$ spatial vari- abilities have similar contributions or whether one is more dominant than the other.

To compare the contributions of $\mathrm{H}_{2} \mathrm{O}$ and $T$ to RHi variabilities, the changes of RHi are separated into the contributions from the changes of $\mathrm{H}_{2} \mathrm{O}$ and $T$. For example, Spichtinger et al. (2005a, b) used radiosonde data on the $\sim 100 \mathrm{~km}$ scale to analyze the formation of ISSRs in the Lagrangian view by large-scale dynamics, such as gravity waves and warm conveyor belts. They pointed out the importance of large-scale cooling during the time evolution of ISSRs based on $100 \mathrm{~km}$-scale Lagrangian model simulations. However, the conditions of ISSRs below the $100 \mathrm{~km}$ scale have not been analyzed, and it is unclear whether $T$ spatial variability is the dominant contribution to RHi spatial variability in the Eulerian view.

In this study, we analyze the individual conditions of ISSRs based on $1 \mathrm{~Hz}$ resolution aircraft observations. This study provides a large number of case studies of ISSRs on the microscale based on the Eulerian view in situ observations. Direct comparisons between ISSRs and their adjacent subsaturated surrounding environments are conducted in order to help understand the factors contributing to the spatial characteristics of ISSRs.

\section{Data sets and instrumentation}

In this work, the spatial variabilities of ISS and RHi are analyzed based on the $1 \mathrm{~Hz}(\sim 230 \mathrm{~m})$ in situ observations made from the National Science Foundation (NSF) Gulfstream V (GV) research aircraft. Two flight campaigns are combined for a comprehensive data set over various latitudes, altitudes and seasons. The NSF Stratosphere Troposphere Analyses of Regional Transport 2008 (START08) campaign (Pan et al., 2010) sampled the upper troposphere/lower stratosphere (UT/LS) over North America in April-June 2008, providing $\sim 90$ transects across the thermal tropopause. The NSF HIAPER Pole-to-Pole Observations (HIPPO) Global field campaign (Wofsy et al., 2011) provided an extensive latitudinal coverage $\left(87^{\circ} \mathrm{N}-67^{\circ} \mathrm{S}\right)$ over North America and the central Pacific Ocean from 2009 to 2011, with $\sim 600$ vertical transects from the surface to the tropical UT or the extratropical UT/LS. The flight tracks of the START08 and HIPPO campaigns being analyzed in this study are shown in Fig. 1. Flights without $\mathrm{H}_{2} \mathrm{O}$ observations are not shown here.

Water vapor was measured by the $25 \mathrm{~Hz}$, open-path vertical-cavity surface-emitting laser (VCSEL) hygrometer (Zondlo et al., 2010). The accuracy and precision of $\mathrm{H}_{2} \mathrm{O}$ measurements are $6 \%$ and $\leq 1 \%$, respectively. Noise levels $(1 \sigma)$ are typically $1-3 \%$ at $25 \mathrm{~Hz}$ for flight measurements. The $\mathrm{H}_{2} \mathrm{O}$ measurements were averaged to 1 s for consistency with the $T$ measurements. The open-path design of the VCSEL hygrometer is critical for the fast response of $\mathrm{H}_{2} \mathrm{O}$ measurements, as surface absorption and sampling problems may complicate the response time of closed-path systems. The 

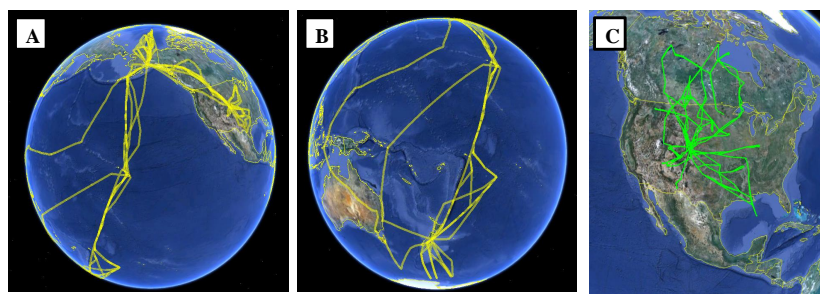

Fig. 1. Google map of START08 and HIPPO flights analyzed in this study. Yellow lines represent flight tracks of HIPPO campaign 1-5 and green lines represent the flight tracks of research flights 4-18 (RF04-RF18) in START08.

fast response of $\mathrm{H}_{2} \mathrm{O}$ measurements here provides the fundamental technical support to our analyses of the contributions of $\mathrm{H}_{2} \mathrm{O}$ and $T$ fluctuations to the RHi spatial variabilities.

Temperature measurements were recorded by the Rosemount temperature probe. The accuracy and precision of $T$ measurements are $0.5 \mathrm{~K}$ and $0.01 \mathrm{~K}$, respectively. The uncertainties in RHi were $8-14 \%$ at $233.15-196 \mathrm{~K}$ after combining the uncertainties from the VCSEL hygrometer $(6 \%)$ and the $T$ probe $( \pm 0.5 \mathrm{~K})$. The saturation vapor pressure is calculated based on the study of Murphy and Koop (2005), which stated that all the commonly used expressions for the vapor pressure over ice are within $1 \%$ of each other at 170-273 K. We do not apply higher frequency observations to our analyses, because no fast $T$ measurements $(<1 \mathrm{~Hz})$ were available in HIPPO, and the fast (sub-Hz) $T$ measurements in START08 were complicated by the presence of ice crystal particles. For these reasons, we only use $1 \mathrm{~Hz}$ data in our analyses.

To compare the ISS variability between regions with and without ice crystals, we use ice crystal concentration measurements to separate these two types of regions. In START08, the ice crystal concentrations were measured by the HIAPER Small Ice Detector Probe (SID-2H) instrument (Cotton et al., 2010). The measurement range of SID-2H is $1-50 \mu \mathrm{m}$. During the HIPPO Global campaign deployments $2-5$, ice crystal concentrations were measured by the two dimension cloud particle imaging (2DC) ice probe (Korolev et al., 2011). The 2DC ice probe has a measurement range of $25-800 \mu \mathrm{m}$, which reports ice crystal number density $N_{\mathrm{c}}$ (in $\mathrm{L}^{-1}$ ). Since the ice crystal concentrations were not measured in HIPPO deployment 1, we only compare the ISSRs with and without the presence of ice crystals during START08 and HIPPO deployments 2-5. Here we use the terminology of "in-cloud" to represent the regions with the presence of ice crystals. We note that these terms of "in cloud" and "clear sky" only represent the conditions of 1-D flight segments at $1 \mathrm{~Hz}$ resolution. For SID-2H measurements, we define the in-cloud regions as locations where the total ice particle concentrations are greater than $0.06 \mathrm{~cm}^{-3}$ during the $1 \mathrm{~Hz}$ measurements. We used $0.06 \mathrm{~cm}^{-3}$ as the threshold for SID$2 \mathrm{H}$ instrument because it represents greater than one parti-

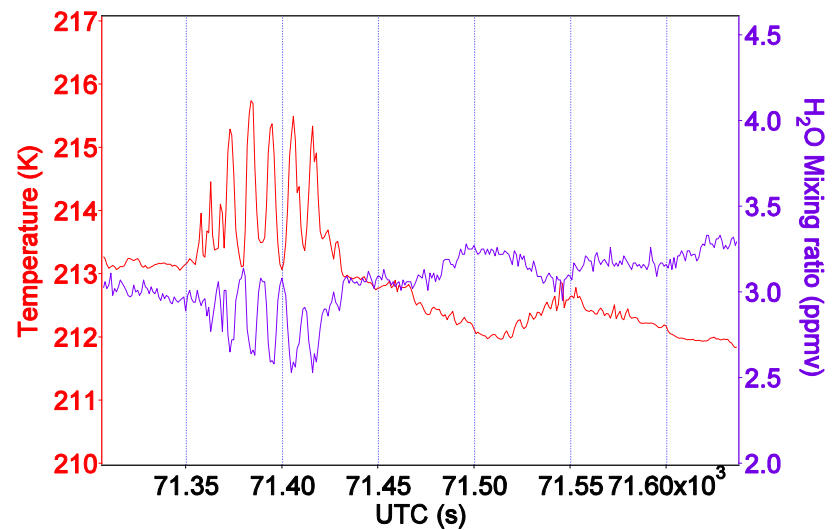

Fig. 2. In-flight synchronization between temperature $(T)$ and water vapor $\left(\mathrm{H}_{2} \mathrm{O}\right)$ measurements. Fluctuations in $T$ (red) and $\mathrm{H}_{2} \mathrm{O}$ (purple) due to a gravity wave were observed during RF08 of START08. These fast fluctuations demonstrate the accurate synchronization of $T$ and $\mathrm{H}_{2} \mathrm{O}$ measurements at the $1 \mathrm{~Hz}$ timescale.

cle per second under the sampling rate of $16 \mathrm{~cm}^{3} \mathrm{~s}^{-1}$. This measurement range is where the SID-2H ice probe functions well for distinguishing between ice crystals and liquid aerosols. For 2DC measurements, we define the in-cloud regions to be where $N_{\mathrm{c}}$ is greater than zero. The remaining regions are considered to be clear-sky regions. We note that there might be a small amount of data that should be incloud but are categorized as clear-sky condition, but these data only contribute to a very small percentage of the total clear-sky data. For example, the SID-2H measurements at $0<N_{\mathrm{c}}<0.06 \mathrm{~cm}^{-3}$ could be either liquid aerosols or ice crystals, but these data only contribute to $1.9 \%$ of the total clear-sky data at $T \leq-40^{\circ} \mathrm{C}$. In addition, for the 2DC probe, ice crystals smaller than $25 \mu \mathrm{m}$ are not detected. But according to the measurements of SID-2H, the observations with ice crystal mean diameter $<25 \mu \mathrm{m}$ is only $1.6 \%$ with respect to the total clear-sky data at $T \leq-40{ }^{\circ} \mathrm{C}$. Therefore, even if these clear-sky data were indeed clouds, they are not going to impact our results significantly. Other measurements that have been used to help interpret the results include ozone $\left(\mathrm{O}_{3}\right)$, carbon monoxide $(\mathrm{CO})$ and ice water content (IWC). The analyses of $\mathrm{O}_{3}, \mathrm{CO}$ and IWC are based on the measurements from the START08 campaign only. In START08, $\mathrm{O}_{3}$ was measured by the NCAR dual-beam ultraviolet absorption photometer with an accuracy of $5 \%$ and precision of $5 \%$ (Tilmes et al., 2010). CO was measured using the NCAR vacuum ultraviolet resonance fluorescence instrument with an accuracy of $9 \%$ and precision of 0.8 ppbv (Tilmes et al., 2010). Total water content was measured by the University of Colorado (CU) tunable diode laser hygrometer with an accuracy of 20-25\% and precision of 5\% (Davis et al., 2007). The IWC value is derived by deducting the water vapor measurements of VCSEL hygrometer from the total water content measurements of the $\mathrm{CU}$ hygrometer. 
Because any synchronization delays between the $\mathrm{H}_{2} \mathrm{O}$ and $T$ measurements would impact our analyses of their contributions to the RHi fluctuations, we demonstrate the in-flight synchronization between the $T$ and $\mathrm{H}_{2} \mathrm{O}$ measurements with the special case of a gravity wave observed in START08 research flight (RF) 08 (Fig. 2). We note that this gravity wave has unusually high frequency and magnitude as well as a clearly observable wave structure, which were not typically seen during the START08 and HIPPO flight campaigns. In general, as the aircraft horizontally transects through a gravity wave near the tropopause, the $\mathrm{H}_{2} \mathrm{O}$ concentration and $T$ values are expected to anticorrelate with each other. In this case, the gravity wave has $\sim 10$ oscillations with an average period of $\sim 8 \mathrm{~s}(\sim 1800 \mathrm{~m})$. The peaks of $\mathrm{H}_{2} \mathrm{O}$ concentration match well with the troughs of $T$ values in individual periods, which demonstrate that $T$ and $\mathrm{H}_{2} \mathrm{O}$ measurements have a fast, synchronized response to the fluctuations of the atmospheric conditions at $1 \mathrm{~Hz}$ resolution.

\section{Methods}

\subsection{Method for analyzing RHi spatial variability}

Based on the Clausius-Clapeyron equation, the variability of RHi is directly contributed by the variabilities of $\mathrm{H}_{2} \mathrm{O}$ and $T$. Although previous studies have analyzed the spatial variabilities of $T$ and $\mathrm{H}_{2} \mathrm{O}$ (Cho et al., 2000) and the variance scaling of $T$ and $\mathrm{H}_{2} \mathrm{O}$ (Kahn and Teixeira, 2009; Kahn et al., 2011), it is still unclear for individual ISSRs how the higher RHi values inside ISSRs than their adjacent subsaturated air are derived from $T$ and $\mathrm{H}_{2} \mathrm{O}$ spatial variabilities. In addition, although it has been shown for the boundary layer that $T$ contribution to RH variability becomes more important from mesoscale to microscale (Price and Wood, 2002), it has not been analyzed for the RHi in the UT as to whether the $T$ contribution follows similar trend.

To quantify the contributions from $\mathrm{H}_{2} \mathrm{O}$ and $T$ spatial variabilities to the RHi spatial variability, we separate the change of RHi ( $d$ RHi) into two parts: the contributions from $\mathrm{H}_{2} \mathrm{O}$ partial pressure variability $\left(d \mathrm{RHi}_{q}\right)$ and those from $T$ variability $\left(d \mathrm{RHi}_{T}\right)$. Applying the chain rule to $d \mathrm{RHi}$, we get

$d \mathrm{RHi}=d \frac{e}{e_{\mathrm{S}}}=e d \frac{1}{e_{\mathrm{S}}}+\frac{1}{e_{\mathrm{S}}} d e=d \mathrm{RHi}_{T}+d \mathrm{RHi}_{q} ;$

here $e$ is the $\mathrm{H}_{2} \mathrm{O}$ partial pressure, and $e_{\mathrm{s}}$ is the saturation vapor pressure over ice calculated based on the equation from Murphy and Koop (2005). Because aircraft sampling is discretely distributed, we use the difference between two points as an approximation of the derivative. We assume that the magnitudes of $d\left(1 / e_{\mathrm{s}}\right)$ and $d e$ terms are relatively small, such that only the first terms of the Taylor expansion are considered in Eqs. (1b) and (1c):

$d \frac{1}{e_{\mathrm{S}}} \approx \Delta\left(\frac{1}{e_{\mathrm{S}}}\right)=\frac{1}{e_{s, 1}}-\frac{1}{e_{s, 2}}$, $d e \approx \Delta(e)=e_{1}-e_{2}$.

We also separate the changes in $e$ term $d e$ into the contributions from the variability of $\mathrm{H}_{2} \mathrm{O}$ volume mixing ratio $\left(\mathrm{H}_{2} \mathrm{OMR}, \mathrm{ppmv}\right)$ and the variability of total pressure $(P$, $P a$ ). Similarly, only the first terms of the Taylor expansion are considered for $d \mathrm{H}_{2} \mathrm{OMR}$ and $d P$, assuming that changes are relatively small. The contributions of the $\mathrm{H}_{2} \mathrm{OMR}$ and $P$ variabilities to $d e$ are defined as $d \mathrm{e}_{\mathrm{H}_{2} \mathrm{OMR}}$ and $d \mathrm{e}_{P}$, respectively:

$d e=d\left(\mathrm{H}_{2} \mathrm{OMR} \cdot P\right)=P \cdot d \mathrm{H}_{2} \mathrm{OMR}+\mathrm{H}_{2} \mathrm{OMR} \cdot d P$
$=d e_{\mathrm{H}_{2} \mathrm{OMR}}+d e_{P}$,

$d \mathrm{H}_{2} \mathrm{OMR} \approx \Delta\left(\mathrm{H}_{2} \mathrm{OMR}\right)=\mathrm{H}_{2} \mathrm{OMR}_{1}-\mathrm{H}_{2} \mathrm{OMR}_{2}$,

$d P \approx \Delta(P)=P_{1}-P_{2}$

To directly compare how $\mathrm{H}_{2} \mathrm{O}$ and $T$ variabilities contribute to individual ISSR conditions, we compare the RHi values inside and outside of each ISSR. We calculated the difference between the $\mathrm{RHi}_{\text {max }}$ inside an ISSR (RHimax inside $_{\text {) }}$ and the RHi of the horizontal adjacent subsaturated regions $\left(\mathrm{RHi}_{\text {outside }}\right)$. This difference is defined as $d \mathrm{RHi}_{\text {max }}$. Here we use the mean RHi of the horizontally adjacent ( $\pm 1 \mathrm{~s})$ subsaturated air as representative of $\mathrm{RHi}_{\text {outside, although other }}$ larger scales (e.g., $\pm 2 \mathrm{~s}, \pm 3 \mathrm{~s}$, up to $\pm 30 \mathrm{~s}$ ) of subsaturated conditions have also been tested to verify our results. We apply Eqs. (1) and (2) to $d \mathrm{RHi}_{\max }$ to quantify how $d \mathrm{RHi}_{\max }$ in each ISSR segment is composed of a pair of $d \mathrm{RHi}_{q}$ and $d \mathrm{RHi}_{T}$.

Similarly, we analyze the horizontal spatial variabilities of all RHi (including both ISS and non-ISS) using Eq. (1). Here the RHi difference between the mean RHi values of two horizontally $(d P<1 \mathrm{hPa})$ adjacent segments is defined as $d$ RHi. The RHi variability with $d P<10 \mathrm{hPa}$ as well as that with no pressure restriction are also analyzed. Different scales of horizontal segments are analyzed from $\sim 230 \mathrm{~m}$ up to $\sim 115 \mathrm{~km}$. The maximum scale of the horizontal segment is limited to $115 \mathrm{~km}(\sim 500 \mathrm{~s})$ because of the strict pressure restriction $(d P<1 \mathrm{hPa})$ and the decreasing number of consecutive flight samples with the increasing scale. We apply Eqs. (1) and (2) to the $d \mathrm{RHi}$ of each pair of horizontal adjacent segments and quantify how the fluctuations of $\mathrm{H}_{2} \mathrm{O}$ and $T$ contribute to each $d \mathrm{RHi}$.

\subsection{Method for analyzing the mean absolute deviation of RHi}

Another similar method for analyzing contributions to the RHi field is to examine the variabilities around the mean value for a certain length scale. In this regard, we also analyze the RHi horizontal spatial variability in terms of the mean absolute deviation of RHi ( $\sigma \mathrm{RHi}), \sigma \mathrm{RHi}$ is calculated 
Table 1. Data distribution and sampling range in this work.

\begin{tabular}{|c|c|c|c|c|}
\hline Data distribution & $\begin{array}{l}\mathrm{NH} \\
\left(0-87^{\circ} \mathrm{N}\right)\end{array}$ & $\begin{array}{l}\mathrm{SH} \\
\left(0-67^{\circ} \mathrm{S}\right)\end{array}$ & $\begin{array}{l}\text { Tropics } \\
\left(30^{\circ} \mathrm{S}-30^{\circ} \mathrm{N}\right)\end{array}$ & $\begin{array}{l}\text { Extratropics } \\
\left(30^{\circ} \mathrm{N}-87^{\circ} \mathrm{N},\right. \\
\left.30-67^{\circ} \mathrm{S}\right)\end{array}$ \\
\hline Flight hour of all $T$ range (h) & 296.9 & 104.9 & 92.6 & 309.2 \\
\hline Flight hour of $T \leq-40^{\circ} \mathrm{C}(\mathrm{h})$ & 136.3 & 31 & 21.4 & 145.9 \\
\hline ISS observation (h) & 9.3 & 1.5 & 1.0 & 9.8 \\
\hline$T(\mathrm{~K}) \min ; \max$ & $204.2 ; 311.0$ & $195.9 ; 305.3$ & $204.4 ; 311.0$ & $195.9 ; 309.6$ \\
\hline$P(\mathrm{mb}) \mathrm{min} ; \max$ & $133 ; 1023$ & $133 ; 1039$ & $134 ; 1024$ & $133 ; 1039$ \\
\hline $\mathrm{H}_{2} \mathrm{O}$ (ppmv) min; $\max$ & $1.87 ; 37500$ & $1.45 ; 38900$ & $2.41 ; 38900$ & $1.45 ; 28900$ \\
\hline
\end{tabular}

for individual horizontal $(d P<1 \mathrm{hPa})$ segments during the aircraft sampling by comparing each $1 \mathrm{~Hz}$ RHi value within that segment with the mean RHi value (Eq. 3a). The average contributions from the variabilities of $\mathrm{H}_{2} \mathrm{O}$ and $T$ to the magnitude of $\sigma \mathrm{RHi}$ inside this segment are defined as $\sigma \mathrm{RHi}_{q}$ and $\sigma \mathrm{RHi}_{T}$ in Eqs. (3b) and (3c), respectively. The calculations of $\sigma \mathrm{RHi}_{q}$ and $\sigma \mathrm{RHi}_{T}$ consider the signs (positive or negative) of the $\mathrm{H}_{2} \mathrm{O}$ and $T$ contributions to $\sigma$ RHi by using the $\operatorname{sgn}\left(\mathrm{x}_{q}\right)$ and $\operatorname{sgn}\left(\mathrm{x}_{T}\right)$ terms, respectively.

$$
\begin{aligned}
& \sigma \mathrm{RHi}=\frac{\sum_{k=1}^{N}\left(\left|\mathrm{RHi}_{k}-\overline{\mathrm{RHi}}\right|\right)}{N-1}, \\
& \sigma \operatorname{RHi}_{q}=\frac{\sum_{k=1}^{N}\left(\operatorname{sgn}\left(x_{q}\right)\left|\overline{\frac{1}{e_{s}}}\left(e_{k}-\bar{e}\right)\right|\right)}{N-1}, \\
& \sigma \mathrm{RHi}_{T}=\frac{\sum_{k=1}^{N}\left(\operatorname{sgn}\left(x_{T}\right)\left|\bar{e}\left(\frac{1}{e_{\mathrm{s} k}}-\overline{\overline{1}}\right)\right|\right)}{N-1}, \\
& \operatorname{sgn}\left(x_{q}\right)=1 \text {, if }\left(\mathrm{RHi}_{k}-\overline{\mathrm{RHi}}\right)\left(\frac{\overline{1}}{e_{\mathrm{s}}}\left(e_{k}-\bar{e}\right)\right) \geq 0, \\
& \operatorname{sgn}\left(x_{q}\right)=-1, \text { if }\left(\mathrm{RHi}_{k}-\overline{\mathrm{RHi}}\right)\left(\frac{\overline{1}}{e_{\mathrm{s}}}\left(e_{k}-\bar{e}\right)\right)<0, \\
& \operatorname{sgn}\left(x_{T}\right)=1, \text { if }\left(\mathrm{RHi}_{k}-\overline{\mathrm{RHi}}\right)\left(\bar{e}\left(\frac{1}{e_{\mathrm{s} k}}-\overline{\overline{1}} \frac{\overline{e_{\mathrm{S}}}}{}\right) \geq 0,\right. \\
& \operatorname{sgn}\left(x_{T}\right)=-1 \text {, if }\left(\mathrm{RHi}_{k}-\overline{\mathrm{RHi}}\right)\left(\bar{e}\left(\frac{1}{e_{\mathrm{S} k}}-\frac{\overline{1}}{e_{\mathrm{S}}}\right)\right)<0 \text {, }
\end{aligned}
$$

where $N$ is the sample size, and $\overline{\mathrm{RHi}}, \overline{\frac{1}{e_{\mathrm{s}}}}$ and $\bar{e}$ are the mean values of $\mathrm{RHi}, \frac{1}{e_{\mathrm{s}}}$ and $e$ in the sampling range, respectively. Similar to the $d \mathrm{RHi}$ analyses of the horizontal RHi variability, the maximum scale of $\sigma \mathrm{RHi}$ is also limited to $115 \mathrm{~km}(N=500)$ because of the strict pressure restriction $(d P<1 \mathrm{hPa})$ and the decreasing number of consecutive flight samples with increasing scale. According to these definitions, when the changes in $\mathrm{H}_{2} \mathrm{O}$ concentration have the same sign as the changes in $\mathrm{RHi}$, the $\mathrm{H}_{2} \mathrm{O}$ contribution to RHi fluctuation is positive, as is the $\sigma \mathrm{RHi}_{q}$ term. Similarly, when the changes in $T$ have the opposite sign as the changes in RHi, $\sigma \mathrm{RHi}_{T}$ term is positive. The $\sigma \mathrm{RHi}$ term should always be greater or equal to zero, because it is the sum of absolute values. Therefore at least one of the terms of $\sigma \mathrm{RHi}_{q}$ and $\sigma \mathrm{RHi}_{T}$ should be non-negative, which means that at least one of the $\mathrm{H}_{2} \mathrm{O}$ or $T$ fluctuations positively contributes to the direction of RHi fluctuation. For example, for a segment of aircraft observations of fluctuating $\mathrm{RHi}$, when the $\mathrm{RHi}$ value of one point is smaller than the mean RHi value, there should be lower $\mathrm{H}_{2} \mathrm{O}$ concentration or higher $T$, or both, at this point with respect to the mean $\mathrm{H}_{2} \mathrm{O}$ and $T$ values of the segment. Using Eq. (3) can help us separately quantify the contributions of $\mathrm{H}_{2} \mathrm{O}$ and $T$ to the fluctuation of $\mathrm{RHi}$, regardless of whether the RHi change is positive or negative at each point.

We note that the current method differs from the previous variability analyses of Gierens et al. (2007). Although Gierens et al. (2007) first decomposed $d$ RHi into the fluctuations of $\mathrm{H}_{2} \mathrm{O}$ and $T$ (similar to Eq. (1a) in this work), they used the standard deviations of $\mathrm{H}_{2} \mathrm{O}$ and $T$ to compare the contributions of $\mathrm{H}_{2} \mathrm{O}$ and $T$ variabilities to $\mathrm{RHi}$ variability. The standard deviations of $\mathrm{H}_{2} \mathrm{O}$ and $T$ do not account for the direction of their changes, and therefore cannot address whether the fluctuations of $\mathrm{H}_{2} \mathrm{O}$ and $T$ are in the same (or opposite) direction with RHi fluctuation. For example, for a time series of continuously increasing RHi with increasing $\mathrm{H}_{2} \mathrm{O}$ and $T$, the increasing $T$ actually provides a negative contribution to the increasing RHi along the time series. But this negative contribution of increasing $T$ is treated as the same as the positive contribution of increasing $\mathrm{H}_{2} \mathrm{O}$ when comparing the standard deviations of $T$ and $\mathrm{H}_{2} \mathrm{O}$. In other words, using the expression of standard deviation for this type of analyses would overestimate the contribution to $\mathrm{RHi}$ variability when the changes of $\mathrm{H}_{2} \mathrm{O}(T)$ are in the opposite (same) direction of RHi changes.

\section{Results and discussion}

\subsection{Overall aircraft sampling of ISS and ISSRs}

The data distribution and sampling range of this work are shown in Table 1 . The observations include $\sim 300 \mathrm{~h}$ and $\sim 100 \mathrm{~h}$ in the Northern and Southern Hemisphere (NH and $\mathrm{SH})$, as well as $\sim 310 \mathrm{~h}$ and $\sim 90 \mathrm{~h}$ in the extratropical $\left(30^{\circ} \mathrm{S}-\right.$ $67^{\circ} \mathrm{S}$ and $\left.30^{\circ} \mathrm{N}-87^{\circ} \mathrm{N}\right)$ and tropical regions $\left(30^{\circ} \mathrm{S}-30^{\circ} \mathrm{N}\right)$, 


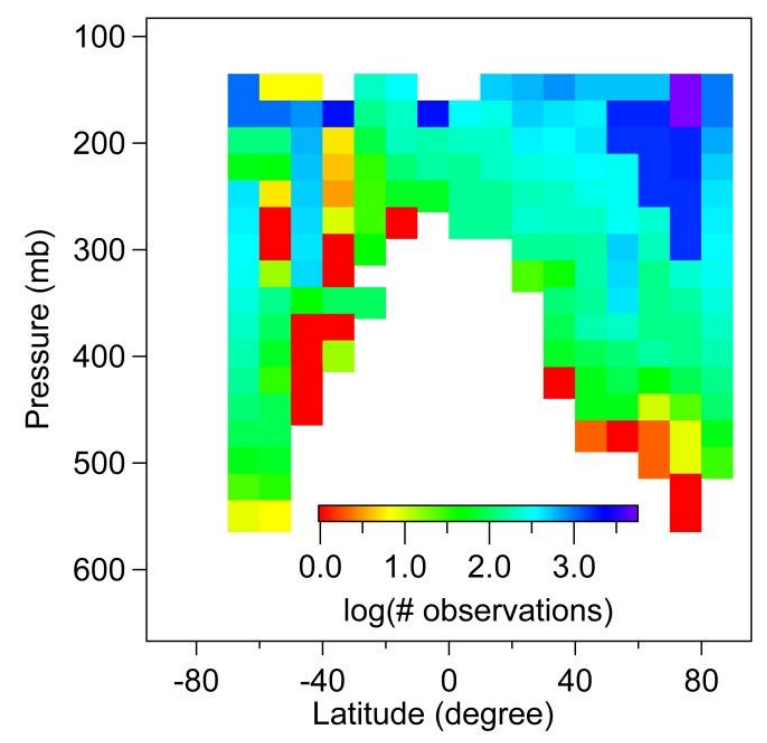

Fig. 3. Distribution of the number of observations at $T \leq-40^{\circ} \mathrm{C}$ in the latitudinal and vertical view for the START08 and HIPPO campaigns. The color code shows the number of observations in each $10^{\circ} \times 25 \mathrm{mb}$ bin in the log scale.

respectively. The overall observations of $T, P$ and $\mathrm{H}_{2} \mathrm{O}$ range from 196 to $311 \mathrm{~K}, 133$ to $1039 \mathrm{mb}$ and 1.5 to $39000 \mathrm{ppmv}$, respectively. The whole data set consists of $\sim 217 \mathrm{~h}$ of $1 \mathrm{~Hz}$ observations at $T \leq-40{ }^{\circ} \mathrm{C}(\sim 62 \mathrm{~h}$ from START08, $\sim 155 \mathrm{~h}$ from HIPPO). Unless noted otherwise, we restrict our analyses to $T \leq-40{ }^{\circ} \mathrm{C}$ to ensure that no ambiguities from supercooled liquid water are involved (Murphy and Koop, 2005). The overall distribution of the observations at $T \leq-40^{\circ} \mathrm{C}$ is illustrated in Fig. 3 in the latitudinal and vertical view. Here the number of observations is binned by $10^{\circ}$ in latitude and $25 \mathrm{mb}$ in pressure. Fig. 3 shows that our observations from the HIPPO and START08 campaigns cover a wide latitudinal range $\left(87^{\circ} \mathrm{N}-67^{\circ} \mathrm{S}\right)$ and vertical range $(\sim 130-550 \mathrm{mb})$. Note that the NSF GV aircraft ceiling $(<\sim 15 \mathrm{~km})$ prevents us from sampling the majority of the tropical tropopause layer.

Of the 217 hours at $T \leq-40^{\circ} \mathrm{C}$, there are $\sim 11 \mathrm{~h}$ of ISS observations (5\%). For these ISS observations, $87 \%$ and $13 \%$ of them were in the $\mathrm{NH}$ and $\mathrm{SH}$, respectively. In addition, $90 \%$ and $10 \%$ of these ISS were observed in the extratropical and tropical regions, respectively. We note that although there are fewer ISS observations in the SH and tropical regions at $T \leq-40^{\circ} \mathrm{C}$, there are still sufficient amount of flight hours in the $\mathrm{SH}(\sim 105 \mathrm{~h})$ and in the tropical regions $(\sim 93 \mathrm{~h}$ ) for our analyses of RH variability at all $T$ condition. The total ISS observations are composed of 1542 individual ISSR segments. Here an ISSR is defined as the 1-D segment where ISS is observed to be spatially continuous. Similar to previous analyses, ISSRs include both clear-sky and in-cloud conditions (Spichtinger et al., 2005b). For the data set with ice particle measurements (i.e., START08 campaign

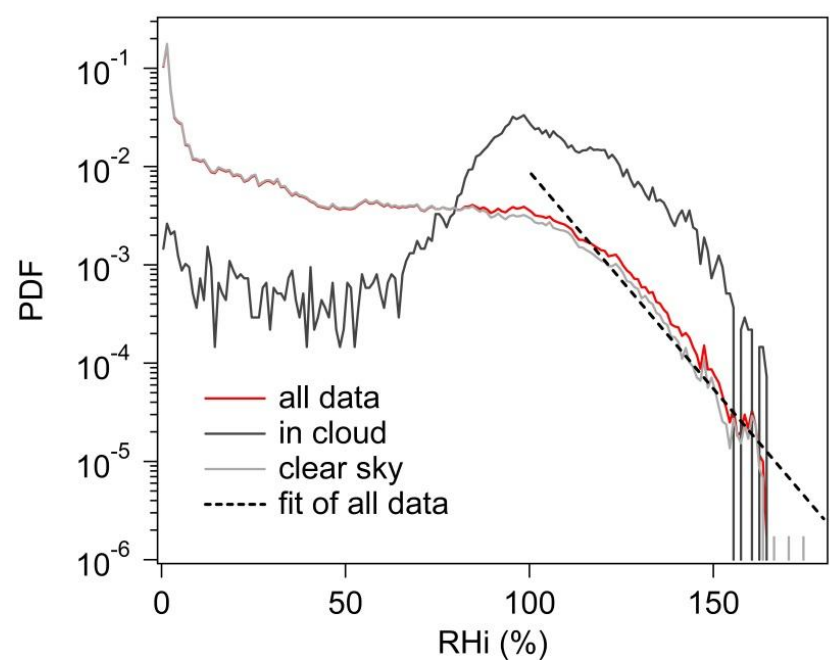

Fig. 4. Probability density functions (PDFs) of RHi for $1 \mathrm{~Hz}$ START08 and HIPPO 2-5 data. Different colors represent RHi of all data (red), the clear-sky (light grey) and the in-cloud data (dark grey). For all the $1 \mathrm{~Hz}$ data (red), the PDF of RHi $>100 \%$ follows an exponential decay: $\ln (\mathrm{PDF})=a+b \times \mathrm{RHi}$, where $a=5.4 \pm 0.5$, $b=-0.10 \pm 0.003( \pm \sigma, \sigma$ is 1 standard deviation $)$.

and HIPPO deployments 2-5), $97 \%$ of total observations at $T \leq-40^{\circ} \mathrm{C}$ were in clear sky and $3 \%$ were in cloud. For the clear-sky conditions, $5 \%$ were ice supersaturated. For the incloud conditions, $54 \%$ were ice supersaturated.

To demonstrate the general consistency with past work for in-cloud measurements, we examine the probability density function (PDF) of the RHi for in-cloud conditions. The PDF of $1 \mathrm{~Hz}$ in-cloud RHi in START08 and HIPPO campaigns 25 peaks around $95.5-98.5 \%$ (Fig. 4). Ovarlez et al. (2002) analyzed $1 \mathrm{~Hz}$ aircraft observations at Prestwick, Scotland $\left(55^{\circ} \mathrm{N}\right)$, and showed that the PDF of in-cloud RHi peaks at $97.5 \%$ at $T \leq-40^{\circ} \mathrm{C}$, which is very consistent with our observations. Another previous study of Krämer et al. (2009) used $10 \%$ as RHi bin size for $1 \mathrm{~Hz}$ observation and showed that the in-cloud data peak at $100 \%$. For the larger scale $(\sim 45 \mathrm{~km})$ RHi distribution, Kahn et al. (2009) used satellite observations to show that the in-cloud RHi peaks around $80-90 \%$ in the UT. The lower value of the in-cloud RHi peak for the larger scale observations compared with the smaller scale observations is a common feature, as discussed by Dickson et al. (2010), since a shallow layer of ice saturation or ISS embedded within a subsaturated layer may be averaged out by satellite retrievals due to their coarse vertical resolutions. We note that these past studies were conducted at different temperature and altitude ranges. For example, the current analyses on ISS are at 196-233.15 K; the analyses of Krämer et al. (2009) were at 183-240 K; the analyses of Ovarlez et al. (2002) were at $\sim 210-250 \mathrm{~K}$; and the analyses of Kahn et al. (2009) were at $T<243 \mathrm{~K}$ and $\mathrm{H}_{2} \mathrm{O}$ mixing ratio $<15 \mathrm{ppmv}$, which is below $\sim 15 \mathrm{~km}$. In addition, 

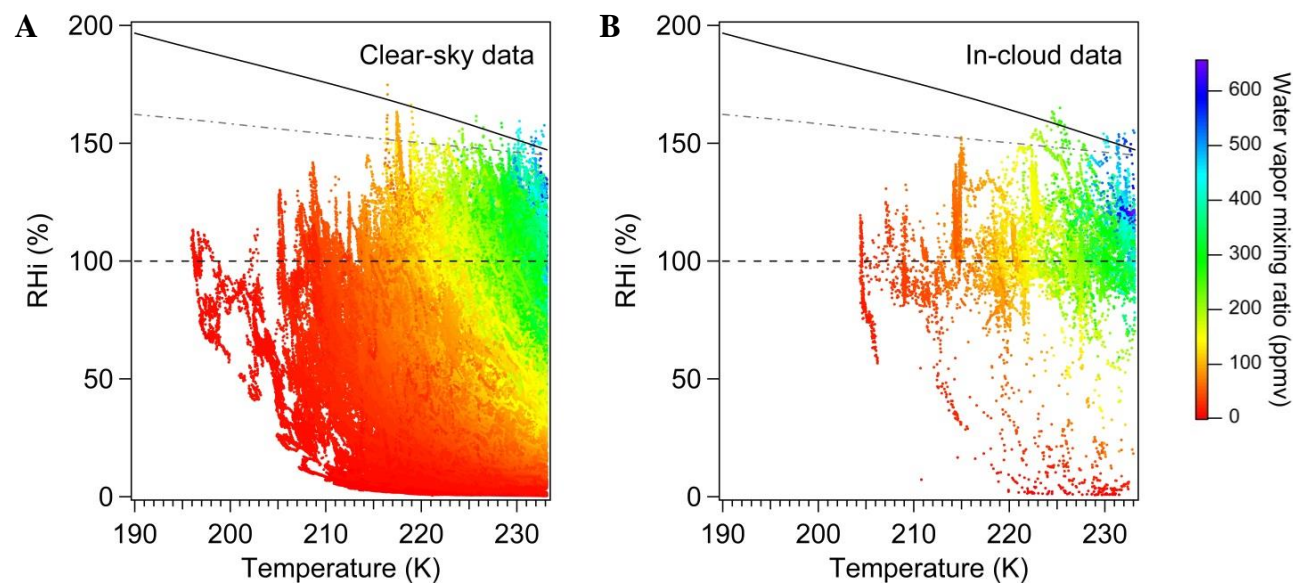

Fig. 5. Distributions of $1 \mathrm{~Hz}$ RHi data at $T \leq-40^{\circ} \mathrm{C}$ for clear-sky (A) and in-cloud (B) conditions. The $1 \mathrm{~Hz}$ RHi data are color-coded with regard to $\mathrm{H}_{2} \mathrm{O}$ mixing ratio (ppmv). The black solid line and the grey dashed line represent the liquid water saturation line and homogeneous freezing line, respectively. The dark dashed line denotes $100 \%$ RHi.

the uncertainties from different measurements may also contribute to the differences in RHi peak; for example, the uncertainty of RHi is $8-14 \%$ in this study.

To further compare with the previous $1 \mathrm{~Hz}$ observations of ISS by Krämer et al. (2009), we analyze the distribution of $1 \mathrm{~Hz}$ RHi data at various $T$ for both clear-sky and incloud conditions. We note that the observations in Krämer et al. (2009) contain much colder conditions that have not been sampled in the START08 and HIPPO campaigns due to the flight ceiling restriction of the GV research aircraft. Figure 5 shows that for both conditions, the RHi observations are almost always at or below the liquid water saturation line calculated based on Murphy and Koop (2005). We note that there are a few points in Fig. 5 that have higher RHi than the liquid water saturation line, but the differences between these points and the liquid water saturation line are still within the combined uncertainties of $8-14 \%$ in RHi. In addition, the observed ISS is mostly at or below the homogeneous freezing threshold of a liquid droplet with $0.5 \mu$ m radius (Koop et al., 2000). These findings are consistent with the RHi distribution with respect to $T$ shown in Krämer et al. (2009) at the same temperature range. We note that the low RHi values around $<20 \%$ for in-cloud data may represent ice crystals that fall into much drier conditions than their initial formation conditions. We also color-coded the RHi data with regard to $\mathrm{H}_{2} \mathrm{O}$ mixing ratio and showed that the $\mathrm{H}_{2} \mathrm{O}$ mixing ratios of most ISS observations (99\%) are above $20 \mathrm{ppmv}$ (orange to purple coloring), where complications from calibration artifacts are less problematic.

\subsection{Spatial characteristics of ISSRs}

A typical time series of the aircraft observations of RHi (black line), $T$ (red dotted line), $\mathrm{H}_{2} \mathrm{O}$ (blue) and altitude (green) are shown in Fig. 6a. The ISSR is defined as the re- gion where RHi is consistently above $100 \%$ (thick red line). For each segment of ISSR, we analyze its spatial characteristics in terms of its length and $\mathrm{RHi}_{\text {max }}$. In addition, we calculate the spacing between the ISSRs. Here these spatial characteristics are analyzed in a horizontal Eulerian view, since the aircraft's horizontal true air speed is always at least $\sim 25$ times greater than its vertical velocity. The distributions of these characteristics of all 1542 ISSRs are shown in Fig. $6 \mathrm{~b}$. The number of events of ISSR length and spacing are shown as red solid dots and green upside-down triangles in Fig. 6b, respectively, and the relationship between ISSR length and $\mathrm{RHi}_{\max }$ value is shown as the open blue triangles. Based on the number of events of ISSR length, the mean and median of ISSR length are $3.5 \mathrm{~km}$ and $0.7 \mathrm{~km}$, respectively. These values are 2 orders of magnitudes smaller than the previously reported mean $(150 \mathrm{~km})$ and median $(50 \mathrm{~km})$ ISSR lengths at $\sim 15 \mathrm{~km}$ resolution (Gierens and Spichtinger, 2000). Because the previous work of Wood and Field (2011) used a power law distribution to fit the distribution of 1-D cirrus cloud chord length, here we also apply a power law fit to the distribution of ISSR lengths (red dotted line in Fig. 6B); that is, $\log _{10}$ (number of events of ISSR) $=a+b \times \log _{10}$ (ISSR length). The intercept and slope of the fit are $4.7 \pm 0.4$ and $-0.77 \pm 0.11$, respectively. The \pm 1 sigma represents 1 standard deviation for all linear fits in this work. The slope $-0.77 \pm 0.11$ of ISSR length distribution observed in this study is comparable with the slope $-1.66 \pm 0.06$ fitted for cirrus cloud length distribution in Wood and Field (2011).

Besides the analyses on ISSR length scale, we also analyze the spacings between the ISSR segments and find them to be very small. The mean and median scales of the spacings are $\sim 47 \mathrm{~km}$ and $\sim 1 \mathrm{~km}$, respectively. Similar to the fit of ISSR length, we apply a power law fit to the distribution of ISSR spacings (green dashed line in Fig. 6B); that is, $\log _{10}$ (number of events of spacing) $=a+b \times \log _{10}$ (length 
of spacing). The intercept and slope of the fit are $3.5 \pm 0.1$ and $-0.40 \pm 0.03$, respectively. The small median value of the spacings suggests that the ISSR segments are closely distributed next to each other, which indicates a very patchy, heterogeneous structure of ISSRs on the microscale that has not been reported before. The 1-D chord lengths of ISSRs cannot be directly treated as the scales of ISSRs in the higher dimensional view, because it is more likely that a larger ISSR will be transected than a smaller one (Gierens and Spichtinger, 2000). Overall, the observed 1-D segment scale of ISSRs $(\sim 1 \mathrm{~km})$ is comparable to the recently observed 1-D median segment scale of cirrus clouds $(\sim 1 \mathrm{~km})$ (Wood and Field, 2011), which may indicate a link between the ISS spatial variability and cirrus spatial heterogeneities.

To examine whether the larger sized ISSRs correlate with larger or smaller RHi values, we calculated the mean $\mathrm{RHi}_{\max }$ value of all ISSRs within each size bin, as shown by the open blue triangles in Fig. $6 \mathrm{~B}$. The result shows that the $\mathrm{RHi}_{\max }$ value increases with increasing ISSR length scale. We apply a linear fit (shown as a blue dotted line in Fig. 6b) to the $\mathrm{RHi}_{\max }$ value versus the log-scale ISSR length; that is, $\mathrm{RHi}_{\text {max }}=a+b \times \log _{10}$ (ISSR length). The intercept and slope of the fit are $64 \pm 5$ and $14 \pm 1$, respectively. Although not shown here, the mean RHi values inside ISSRs also increase as the scales of ISSR segment lengths increase. These findings indicate that large-scale observations may have biases in estimating $\mathrm{RHi}_{\max }$ if the small-scale ISSR segments have been averaged out due to coarse sampling resolution. The correlation between $\mathrm{RHi}_{\max }$ and the ISSR scale shows the importance of understanding the scales of the processes that contribute to the formation of ISSRs, since the scales of the processes might influence not only the size of ISSRs but also their $\mathrm{RHi}_{\text {max }}$ value.

\subsection{Contributions of $\mathrm{H}_{2} \mathrm{O}$ and $T$ spatial heterogeneities to microscale ISSRs}

To help quantify the observed horizontal patchiness of ISSRs, we analyze how the higher RHi inside each ISSR segment occurs comparing to the horizontally adjacent subsaturated regions (non-ISSRs). The RHi differences between ISSRs and non-ISSRs fundamentally result from the differences in $T$ and $\mathrm{H}_{2} \mathrm{O}$ in these regions. There are three ways that a region becomes an ISSR: (1) colder and moister (in terms of absolute $\mathrm{H}_{2} \mathrm{O}$ concentration), (2) colder and drier, or (3) warmer and moister than adjacent non-ISSRs. We note although theoretically case 2 and case 3 include the situation of $\mathrm{H}_{2} \mathrm{O}_{\text {in }}=\mathrm{H}_{2} \mathrm{O}_{\text {out }}$ and $T_{\text {in }}=T_{\text {out }}$, respectively, these conditions almost never happen given the high precision of $\mathrm{H}_{2} \mathrm{O}$ and $T$ measurements. We categorize the horizontal ISSRs into these three types, which include 1094 ISSRs on quasi-isobaric levels $(d P<1 \mathrm{hPa})$. In total, $99 \%$ of 1094 horizontal ISSRs have higher $\mathrm{H}_{2} \mathrm{O}$ inside than outside (cases $1+3$ ), and $73 \%$ have lower $T$ inside than outside (cases
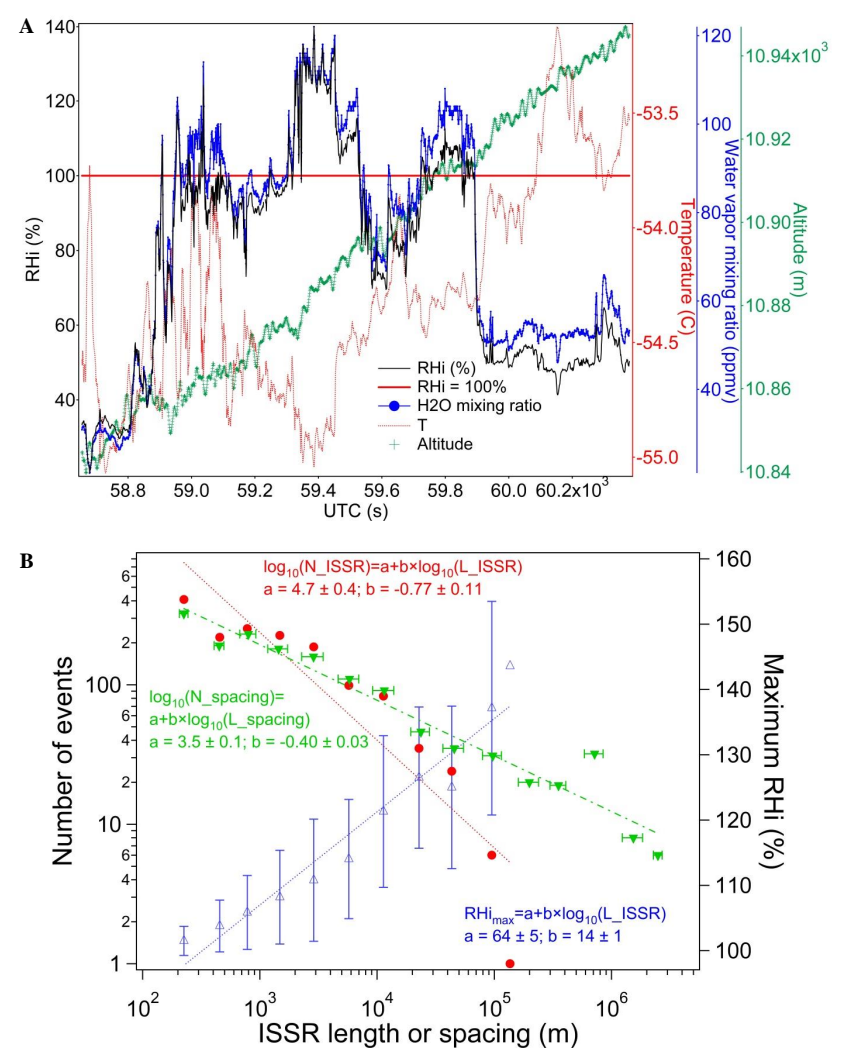

Fig. 6. Aircraft observation of ISSR. (A) An example of the aircraft observation time series of RHi (black line), $\mathrm{H}_{2} \mathrm{O}$ (blue line), $T$ (red dotted line) and altitude (green line). The thick red line denotes $\mathrm{RHi}=100 \%$. The ISSR 1-D segment lengths (L_ISSR) and the spacings (L_spacing) (blank area) between the ISSRs are calculated by multiplying the true air speed with the transect time inside and outside the ISSRs, respectively. The minimum scales are $\sim 230 \mathrm{~m}$ ( $1 \mathrm{~s}$ times $230 \mathrm{~m} \mathrm{~s}^{-1}$ mean true air speed). (B) Both ISSR segment length and spacing are binned by size between $2^{i}$ and $2^{i+1}(\mathrm{~m}), i=$ $1,2,3$. The abscissa shows mean L_ISSR and L_spacing values in each bin. The left ordinate shows the number of events of ISSR segment length (N_ISSR, red dots) and the number of events of ISSR spacing (N_spacing, green upside-down triangles) in each size bin. The right ordinate shows the mean $\mathrm{RHi}_{\text {max }}$ value in each L_ISSR bin (blue open triangles). A power law fit is applied to the N_ISSR versus L_ISSR, i.e., $\log _{10}\left(\mathrm{~N} \_I S S R\right)=a+b \times \log _{10}\left(\mathrm{~L} \_\right.$ISSR $)$(red dotted line). Similarly, a power law fit is applied to N_spacing versus L_spacing, i.e., $\log _{10}\left(\mathrm{~N} \_\right.$spacing $)=a+b \times \log _{10}$ (L_spacing) (green dashed line). A linear fit is applied to $\mathrm{RHi}_{\max }$ versus the logscale L_ISSR, i.e., $\mathrm{RHi}_{\max }=a+b \times \log _{10}$ (L_ISSR) (blue dotted line). For all linear fits in this study $\pm \sigma$ means \pm 1 standard deviation. Intercepts and slopes of the linear fits for all the graphs in this work are represented by values $a$ and $b$ in the legend, respectively.

1+2) (Fig. 7a). Thus, the ISSRs with higher $\mathrm{H}_{2} \mathrm{O}$ concentrations are more frequent than those with lower $T$.

The frequency analyses above of being colder or moister do not yet address the contributions of $\mathrm{H}_{2} \mathrm{O}$ and $T$ in determining the magnitude of the higher RHi inside each ISSR. Therefore, these contributions need to be placed in 

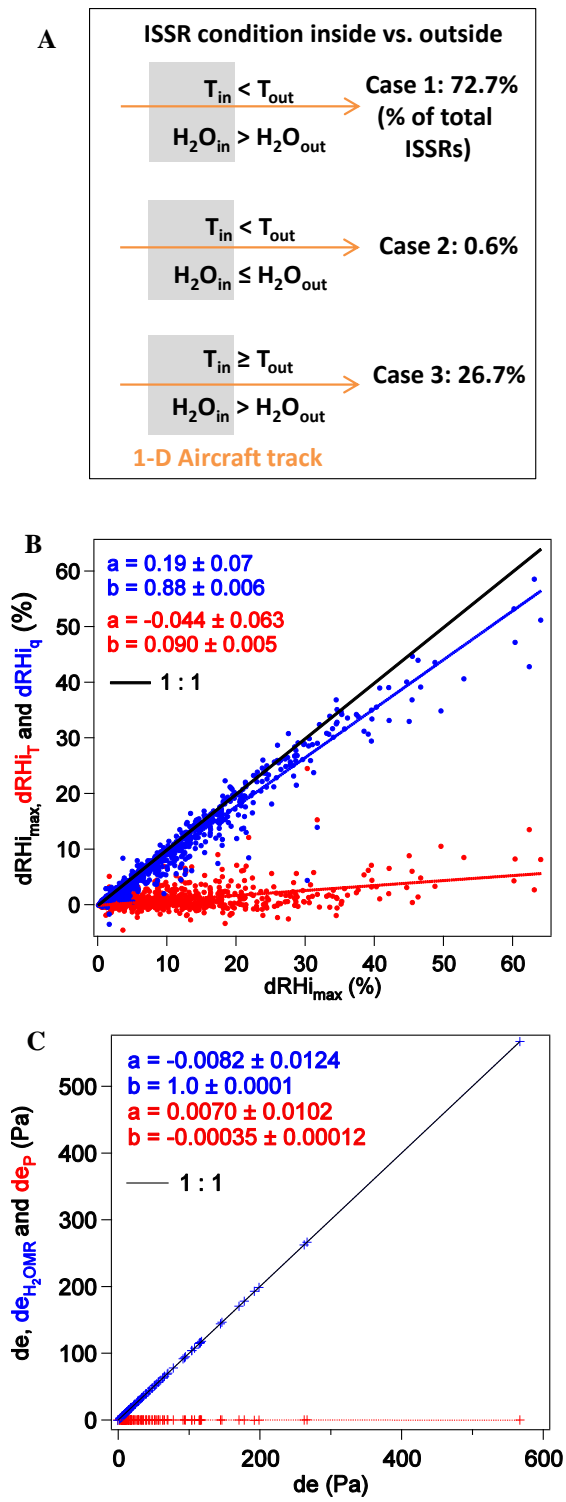

Fig. 7. Correlations between ISSR heterogeneities and $T, \mathrm{H}_{2} \mathrm{O}$ horizontal heterogeneities. (A) ISSR locations are correlated with three cases of $T$ and $\mathrm{H}_{2} \mathrm{O}$ spatial heterogeneities. Grey and blank regions represent ISSRs and the adjacent horizontal $(d P<1 \mathrm{hPa})$ nonISSRs, respectively. $T_{\text {in }}$ and $T_{\text {out }}$ represent the mean $T$ value inside and outside ( $\pm 1 \mathrm{~s}$ ) ISSRs, respectively, and similarly for $\mathrm{H}_{2} \mathrm{O}_{\text {in }}$ and $\mathrm{H}_{2} \mathrm{O}_{\text {out }}$. For 1094 horizontal ISSR segments, $99 \%$ of them correlate with higher $\mathrm{H}_{2} \mathrm{O}$ heterogeneities (cases $1+3$ ) and $73 \%$ correlate with lower $T$ heterogeneities (cases $1+2$ ). (B) $d \mathrm{RHi}_{\max }$ is the difference between the $\mathrm{RHi}_{\max }$ in each ISSR segment and the mean RHi of adjacent $( \pm 1 \mathrm{~s})$ non-ISSRs. The slope of $d \mathrm{RHi}_{\max }(1: 1$ black line) is 1 , which is the linear combination of the fitted slope of $T$ contribution $\left(d \mathrm{RHi}_{T}\right.$, red markers; slope: $\left.0.090 \pm 0.005\right)$ and the fitted slope of $\mathrm{H}_{2} \mathrm{O}$ contribution $\left(d \mathrm{RHi}_{q}\right.$, blue markers; slope: $0.88 \pm 0.006)$. (C) Similar to (B), but decomposes the changes of $\mathrm{H}_{2} \mathrm{O}$ partial pressure term (de, black $1: 1$ line) into the contributions from the changes in total pressure $\left(d e_{P}\right.$, red dots) and contributions from the changes of $\mathrm{H}_{2} \mathrm{O}$ volume mixing ratio $\left(d \mathrm{e}_{\mathrm{H}_{2} \mathrm{OMR}}\right.$, blue dots). The slope of $d e$ is almost all contributed by the fitted slope of $d e_{\mathrm{H}_{2} \mathrm{OMR}}$. comparable terms from Eq. (1). The $d \mathrm{RHi}_{\max }$ in each ISSR segment is contributed by a pair of $d \mathrm{RHi}_{q}$ (Fig. 7b, blue dot) and $d \mathrm{RHi}_{T}$ (red dot). The slopes of the linear fits represent the ratio of the total contributions, which are $0.88 \pm 0.006$ and $0.09 \pm 0.005$ for $\mathrm{H}_{2} \mathrm{O}$ and $T$, respectively. Thus the higher $\mathrm{RHi}_{\max }$ magnitude inside ISSRs compared to outside is mainly $(88 \%)$ contributed by $\mathrm{H}_{2} \mathrm{O}$ variability. The sum of slopes does not exactly equal 1 since we only consider the first terms of the Taylor expansion of the derivatives of $e$ and $1 / e_{\mathrm{S}}$ (see Sect. 3.1). We note that for the linear fit of $d \mathrm{RHi}_{q}$ or $d \mathrm{RHi}_{T}$, the (\%) sign in the intercept is omitted in order to be consistent with the RHi value on the ordinate. For example, the intercept for the fit of $d \mathrm{RHi}_{q}$ in Fig. 7b stands for 0.19 $(\%) \pm 0.07$ (\%), which is very close to zero. This is because when $d \mathrm{RHi}_{\text {max }}$ approaches zero, the $d \mathrm{RHi}_{q}$ and $d \mathrm{RHi}_{T}$ term should also approach zero. The $d \mathrm{RHi}_{q}$ term is further analyzed by quantifying the contributions from total pressure and $\mathrm{H}_{2} \mathrm{O}$ volume mixing ratio using Eq. (2) (Fig. 7c). The changes in $\mathrm{H}_{2} \mathrm{O}$ partial pressure (de) are almost exclusively $(100 \% \pm 0.01 \%)$ the result of the changes of $\mathrm{H}_{2} \mathrm{O}$ mixing ratio and not due to total pressure changes.

The above analyses compared ISSRs with their horizontally adjacent $(d P<1 \mathrm{hPa})$ subsaturated air (non-ISSRs) within $\pm \sim 230 \mathrm{~m}$ from the ISSR boundary. In order to demonstrate that the strong contribution of $\mathrm{H}_{2} \mathrm{O}$ heterogeneities to $d \mathrm{RHi}_{\max }$ does not vary with the lengths of the non-ISSRs being chosen for the comparisons, we tested our result with various lengths of horizontal adjacent non-ISSRs, ranging from $\sim 230 \mathrm{~m}$ to $6.7 \mathrm{~km}$. Beyond $\sim 6.7 \mathrm{~km}$ length, the intersection with adjacent ISSR segments limits the data availability. The contribution of $\mathrm{H}_{2} \mathrm{O}$ heterogeneities does not vary significantly with the scales of non-ISSRs being chosen for the comparison (Fig. 8).

Considering that the formation of ice crystals inside air parcels can change the distribution of $\mathrm{H}_{2} \mathrm{O}$ by depleting the vapor phase, we also analyze how the presence of ice crystals would change the correlations between high $\mathrm{H}_{2} \mathrm{O}$ heterogeneities and ISS in the Eulerian view. Using data from the START08 and HIPPO campaigns 2-5 when ice crystals were measured, the ISSRs are separated into regions with and without the presence of ice crystals. The contributions of $\mathrm{H}_{2} \mathrm{O}$ and $T$ variabilities to $d \mathrm{RHi}_{\max }$ in these two types of ISSRs are analyzed. For these analyses, $d \mathrm{RHi}_{\max }$ represents the difference between the $\mathrm{RHi}_{\max }$ value of ISSRs and the mean RHi of the horizontally adjacent $( \pm \sim 230 \mathrm{~m})$ subsaturated air. For both the ISSRs with and without the presence of ice crystals, $\mathrm{H}_{2} \mathrm{O}$ variability is the dominant contributor to $d \mathrm{RHi}_{\text {max }}$ (Fig. 9). These results demonstrate that the strong contributions of $\mathrm{H}_{2} \mathrm{O}$ heterogeneities to the spatial characteristics of ISSRs exist before, during and after ice nucleation. 
Table 2. Contributions of $\mathrm{H}_{2} \mathrm{O}$ and $T$ horizontal variabilities to $\mathrm{RH}$ horizontal variabilities at various $T, \mathrm{H}_{2} \mathrm{O}$ and $P$ ranges.

\begin{tabular}{lll|lll|lll}
\hline & Bin by $\mathrm{H}_{2} \mathrm{O}$ & \multicolumn{3}{c|}{ Bin by $T$} & \multicolumn{3}{c}{ Bin by $P$} \\
\hline $\mathrm{H}_{2} \mathrm{O}(\mathrm{ppmv})$ & $d \mathrm{RHi}_{q}$ & $d \mathrm{RHi}_{T}$ & $T\left({ }^{\circ} \mathrm{C}\right)$ & $d \mathrm{RHi}_{q}$ & $d \mathrm{RHi}_{T}$ & $P(\mathrm{hPa})$ & $d \mathrm{RHi}_{q}$ & $d \mathrm{RHi}_{T}$ \\
$<10$ & 0.73 & 0.27 & -80 to -60 & 0.88 & 0.12 & $133-200$ & 0.90 & 0.097 \\
$10-30$ & 0.89 & 0.11 & -60 to -40 & 0.94 & 0.062 & $200-400$ & 0.96 & 0.042 \\
$30-100$ & 0.90 & 0.10 & -40 to -20 & 0.98 & 0.024 & $400-600$ & 0.97 & 0.027 \\
$100-1000$ & 0.95 & 0.046 & $-20-0$ & 0.97 & 0.035 & $600-800$ & 0.96 & 0.041 \\
$>1000$ & 0.96 & 0.038 & $>0$ & 0.94 & 0.059 & $>800$ & 0.94 & 0.061 \\
\hline
\end{tabular}

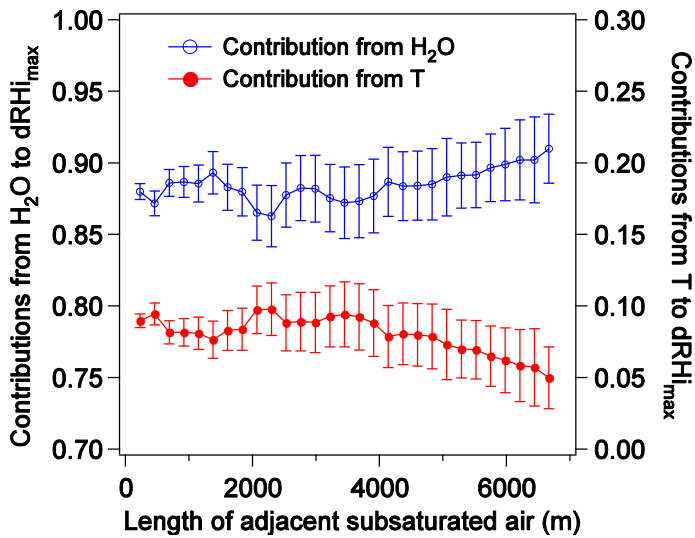

Fig. 8. Contributions from $\mathrm{H}_{2} \mathrm{O}\left(d \mathrm{RHi}_{q}\right.$, left ordinate) and $T$ $\left(d \mathrm{RHi}_{T}\right.$, right ordinate) to $d \mathrm{RHi}_{\max }$ using various scales of horizontally adjacent subsaturated air for comparison. $d \mathrm{RHi}_{q}$ and $d \mathrm{RHi}_{T}$ are in blue circles and red dots, respectively. Error bars represent 1 standard deviation of the linear fit for $d \mathrm{RHi}_{q}$ or $d \mathrm{RHi}_{T}$. The large contributions from $\mathrm{H}_{2} \mathrm{O}$ to $d \mathrm{RHi}$ hold for all length scales of adjacent subsaturated air from $\sim 230 \mathrm{~m}$ to $6.7 \mathrm{~km}$.
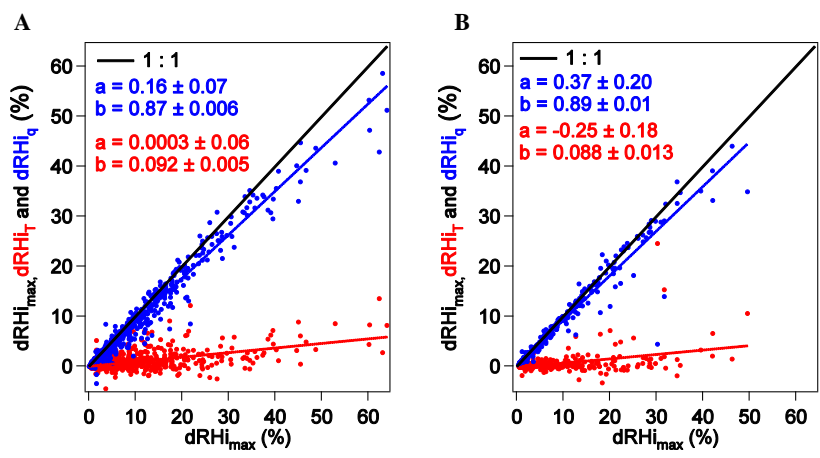

Fig. 9. Contributions from $\mathrm{H}_{2} \mathrm{O}\left(d \mathrm{RHi}_{q}\right)$ and $T\left(d \mathrm{RHi}_{T}\right)$ to the $d \mathrm{RHi}_{\text {max }}$ inside the ISSRs in the clear-sky (A) and in-cloud (B) conditions. The number of ISSRs in clear-sky (A) and cloudy (B) conditions is 783 and 273 , respectively.

\subsection{Horizontal spatial variability of all RHi and the contributions from $\mathrm{H}_{2} \mathrm{O}$ and $T$ spatial variability}

Because ISS ultimately derives from non-ISS (subsaturated and saturated) conditions, we further compare the RHi hor-
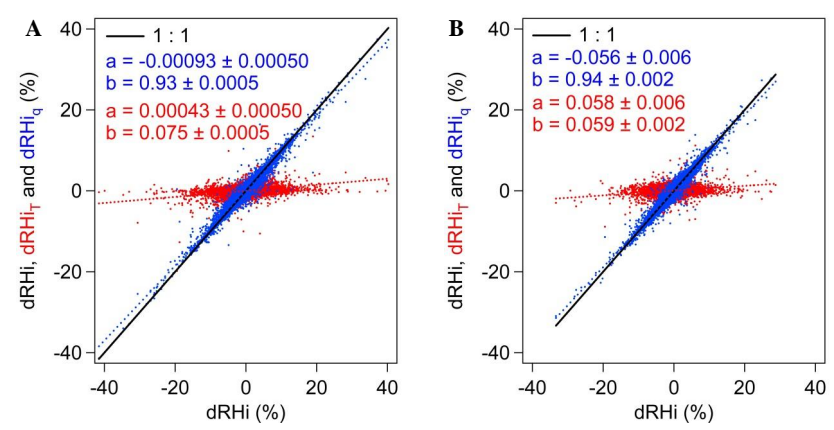

Fig. 10. RHi horizontal variability in non-ISS (subsaturated + saturated) and ISS conditions. (A) $1 \mathrm{~Hz} d \mathrm{RHi}$ analyses for non-ISS (sample size $N=269334$ ), and (B) $1 \mathrm{~Hz} d \mathrm{RHi}$ analyses for ISS $(N=17834)$. The large contributions of $\mathrm{H}_{2} \mathrm{O}$ horizontal variability to $d$ RHi do not vary significantly between non-ISS and ISS conditions: $0.93 \pm 0.0005$ (non-ISS) and $0.94 \pm 0.002$ (ISS).

izontal variabilities between ISS (Fig. 10a) and non-ISS (Fig. 10b) conditions. Based on Eq. (1), we analyze the contribution from $\mathrm{H}_{2} \mathrm{O}$ and $T$ to the horizontal RHi variabilities in terms of $d$ RHi. Here $d$ RHi represents the difference of the mean RHi values between one segment and its adjacent segment in the horizontal $(d P<1 \mathrm{hPa})$. The analyses of $1 \mathrm{~Hz} d \mathrm{RHi}$ show large contributions from $\mathrm{H}_{2} \mathrm{O}$ horizontal variabilities for both ISS $(0.93 \pm 0.005)$ and non-ISS $(0.94 \pm 0.002)$ conditions. In addition, if we combine the ISS and non-ISS conditions and analyze the spatial variabilities of all $\mathrm{RHi}$ at $1 \mathrm{~Hz}$ scale (Fig. 11a), $\mathrm{H}_{2} \mathrm{O}$ spatial variabilities contribute $0.93 \pm 0.004$ to the RHi variations. We also analyzed the contribution of $\mathrm{H}_{2} \mathrm{O}$ variability to the variability of all RHi with two less tight pressure restrictions: (1) $d P<10 \mathrm{hPa}$ and (2) no pressure restriction. The results show that the $\mathrm{H}_{2} \mathrm{O}$ contribution to $d \mathrm{RHi}$ for these two scenarios are $0.93 \pm 0.0004,0.93 \pm 0.0004$ at $1 \mathrm{~Hz}$ scale, and $0.84 \pm 0.01$, $0.89 \pm 0.03$ at $23 \mathrm{~km}$ scale, respectively. These results suggest that the pressure restriction does not influence our conclusion of the strong contribution of $\mathrm{H}_{2} \mathrm{O}$ variability to the RHi variability.

To demonstrate that the contribution of $\mathrm{H}_{2} \mathrm{O}$ spatial variability to $d \mathrm{RHi}$ is not an artifact of instrumental noise, we filtered the $1 \mathrm{~Hz}$ data with $\left|d \mathrm{H}_{2} \mathrm{Oppmv}\right| / \mathrm{H}_{2} \mathrm{Oppmv} \leq 3 \%$. After removing these data, the contribution of $\mathrm{H}_{2} \mathrm{O}$ horizontal 
variability to $1 \mathrm{~Hz}$ horizontal $d \mathrm{RHi}$ does not vary significantly, which is $0.96 \pm 0.001$. We note that the precision of the $\mathrm{H}_{2} \mathrm{O}$ measurement is often $<1 \%$, which is much smaller than the criteria used here, such that we are likely removing real atmospheric fluctuations with this procedure. Similarly, when putting a very tight quality control on the precision of $T$ measurement by filtering out the $1 \mathrm{~Hz}$ data with $|d T| \leq 0.1 \mathrm{~K}$, the contribution of $\mathrm{H}_{2} \mathrm{O}$ horizontal variability to $1 \mathrm{~Hz}$ horizontal $d$ RHi does not vary significantly either, which is $0.82 \pm 0.003$. Thus, even if the variabilities of $\mathrm{H}_{2} \mathrm{O}$ and $T$ well above the instrumental precision are filtered out, the $\mathrm{H}_{2} \mathrm{O}$ horizontal variabilities always have large contributions to the RHi horizontal variabilities.

Another method of examining the RHi variabilities is to quantify the absolute deviation from a mean for both ISS and non-ISS conditions (see Eq. 3a-c). Here $\sigma$ RHi represents the mean of the absolute differences between each $1 \mathrm{~Hz}$ RHi and the average RHi value within a certain horizontal segment. For example, at $\sim 2.3 \mathrm{~km}$ scale, the $\sigma$ RHi analyses show that a ratio of $0.92 \pm 0.001$ of the $1 \mathrm{~Hz}$ RHi horizontal variabilities is contributed by the $\mathrm{H}_{2} \mathrm{O}$ horizontal variabilities (Fig 11b). To test whether our results hold for all cloud scales, various scales of $d \mathrm{RHi}$ and $\sigma \mathrm{RHi}$ are chosen. From $\sim 230 \mathrm{~m}$ up to $\sim 115 \mathrm{~km}$, the results all show much larger contributions from the $\mathrm{H}_{2} \mathrm{O}$ horizontal variabilities $(\sim 0.9-0.8)$ to the RHi horizontal variabilities than from the $T$ horizontal variabilities ( 0.1-0.2) (Fig. 11c).

The above analyses of RHi spatial variability are restricted to $T \leq-40^{\circ} \mathrm{C}$. To expand our analyses of $\mathrm{RH}$ spatial variability to various vertical levels, we binned the data by ranges of $T(193-273.15 \mathrm{~K}$ binned by $20 \mathrm{~K}$ and $>273.15 \mathrm{~K}), \mathrm{H}_{2} \mathrm{O}$ $(<10,10-30,30-100,100-1000,>1000$ ppmv) and $P(133-$ 200 and $200-1000 \mathrm{hPa}$ binned by $200 \mathrm{hPa}$ ). We apply the $d$ RHi analyses at $1 \mathrm{~Hz}$ scale to all the relative humidity ( $\mathrm{RH})$ observations from the surface to the UT/LS. The results in Table 2 show that the $\mathrm{H}_{2} \mathrm{O}$ horizontal variabilities always have dominant contributions to $\mathrm{RH}$ horizontal variabilities, and these $\mathrm{H}_{2} \mathrm{O}$ contributions decrease slightly from the surface to the UT/LS, e.g., from $0.94 \pm 0.001$ at $>800 \mathrm{hPa}$ to $0.90 \pm 0.001$ at $133-200 \mathrm{hPa}$. Although not shown in Table 2, the standard deviations of all the $d \mathrm{RHi}_{T}$ and $d \mathrm{RHi}_{q}$ values are smaller than the last digit of these fits. This finding is consistent with the previous findings about the decreasing variances of $\mathrm{H}_{2} \mathrm{O}$ concentrations from the surface to the UT region (Cho et al., 2000; Kahn and Teixeira, 2009; Kahn et al., 2011). In order to examine whether the dominant contribution of $\mathrm{H}_{2} \mathrm{O}$ variability varies with latitudes, seasons and between over land and ocean, we analyzed the contribution of $\mathrm{H}_{2} \mathrm{O}$ and $T$ variabilities to the $1 \mathrm{~Hz} d \mathrm{RHi}$ at different $P$ bins. Table 3 shows that the $\mathrm{H}_{2} \mathrm{O}$ variability contribution at each pressure bin does not vary significantly when binned by latitude $\left(0-30^{\circ} \mathrm{N}, 30^{\circ} \mathrm{N}-60^{\circ} \mathrm{N}, 60^{\circ} \mathrm{N}-87^{\circ} \mathrm{N}, 0-30^{\circ} \mathrm{S}, 30^{\circ} \mathrm{S}-\right.$ $60^{\circ} \mathrm{S}, 60^{\circ} \mathrm{S}-67^{\circ} \mathrm{S}$ ), nor does it vary between observations over land and ocean, or at different times of a year.
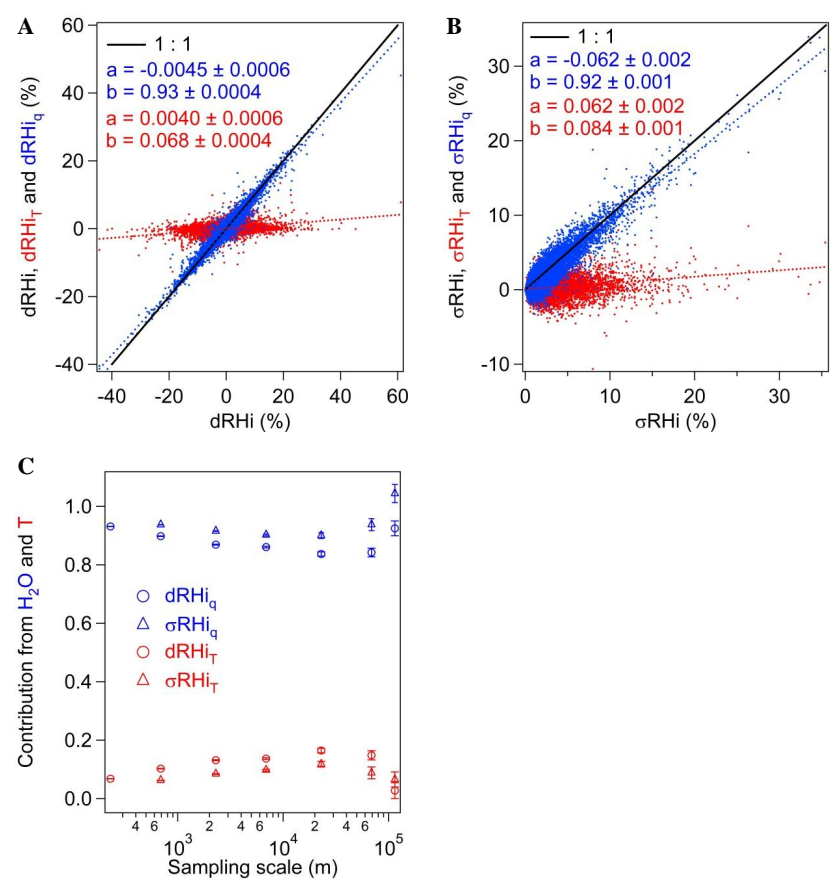

Fig. 11. Contributions to RHi horizontal variability from $\mathrm{H}_{2} \mathrm{O}$ and $T$ horizontal variabilities. The horizontal variability $(d P<1 \mathrm{hPa})$ of all RHi at $T \leq-40{ }^{\circ} \mathrm{C}$ is analyzed, including both ISS and nonISS conditions. Intercept and slope of the linear fits $\left(\mathrm{H}_{2} \mathrm{O}\right.$ : blue dots; $T$ : red dots) are represented by value $a$ and $b$ in the legend, respectively. (A) $1 \mathrm{~Hz} d \mathrm{RHi}$ for all RHi (sample size $N=288827$ ); (B) $1 \mathrm{~Hz} \sigma \mathrm{RHi}$ at $\sim 2.3 \mathrm{~km}(10 \mathrm{~s})$ scale for all RHi $(N=57196)$; (C) scaling of $\mathrm{H}_{2} \mathrm{O}$ and $T$ contributions from $\sim 230 \mathrm{~m}$ to $115 \mathrm{~km}$ (500 s). Sample sizes of $d$ RHi from $\sim 230 \mathrm{~m}$ to $115 \mathrm{~km}$ are 288827 , $85875,20526,6189,1579,372$ and 166, respectively. Sample sizes of $\sigma$ RHi from $\sim 690 \mathrm{~m}$ to $115 \mathrm{~km}$ are $192499,57196,18601,5186$, 1476,768 and 303 , respectively.

\subsection{Dynamical conditions of ISS with tracer-tracer correlation analyses}

To understand the scales of the dynamics that influence the formation of ISSRs, we examine two independent pairs of conservative tracers in extratropical regions, i.e., the $\mathrm{O}_{3}-$ CO correlation (Pan et al., 2004) and the total water content $\left(\mathrm{H}_{2} \mathrm{O}_{\text {tot }}\right)$-wet equivalent potential temperature $\left(\theta_{q}\right)$ correlation (Paluch, 1979). The $\theta_{q}$ values are calculated based on the equations given in Appendix A. For both tracer-tracer correlations in Fig. 12, the grey background points represent the observations including both ISS and non-ISS, while the colored markers represent ISS observations with each type of marker representing one flight. In general, the values of tracer correlations should remain constant (i.e., a single point in the correlation plot) if air parcels are sampled from the same origin (i.e., same chemical tracer values). Otherwise, if mixing between air parcels from different origins has occurred, the correlation between the tracers follows a line or curve. 
Table 3. Contributions of $\mathrm{H}_{2} \mathrm{O}$ and $T$ horizontal variabilities to $\mathrm{RH}$ horizontal variabilities at various $P$ ranges at different latitudes, over land and ocean and at different times of a year.

\begin{tabular}{|c|c|c|c|c|c|c|c|c|c|c|c|c|c|}
\hline \multirow[b]{2}{*}{$P(\mathrm{hPa})$} & \multicolumn{2}{|c|}{$0-30^{\circ} \mathrm{N}$} & \multicolumn{2}{|c|}{$30-60^{\circ} \mathrm{N}$} & \multicolumn{2}{|c|}{$60-87^{\circ} \mathrm{N}$} & \multicolumn{2}{|c|}{$0-30^{\circ} \mathrm{S}$} & \multicolumn{3}{|c|}{$30-60^{\circ} \mathrm{S}$} & \multicolumn{2}{|c|}{$60-67^{\circ} \mathrm{S}$} \\
\hline & $d \mathrm{RHi}_{q}$ & $d \mathrm{RHi}_{T}$ & $d \mathrm{RHi}_{q}$ & $d \mathrm{RHi}_{T}$ & $d \mathrm{RHi}_{q}$ & $d \mathrm{RHi}_{T}$ & $d \mathrm{RHi}_{q}$ & $d \mathrm{RHi}_{T}$ & $d \mathrm{RH}$ & & $d \mathrm{RHi}_{T}$ & $d \mathrm{RHi}_{q}$ & $q \quad d \mathrm{RHi}_{T}$ \\
\hline$<200$ & 0.92 & 0.08 & 0.83 & 0.17 & 0.85 & 0.16 & 0.96 & 0.039 & 0.89 & & 0.11 & 0.96 & 0.04 \\
\hline $200-400$ & 0.98 & 0.015 & 0.94 & 0.056 & 0.95 & 0.051 & 0.98 & 0.019 & 0.97 & & 0.033 & 0.98 & 0.021 \\
\hline $400-600$ & 0.98 & 0.023 & 0.97 & 0.033 & 0.97 & 0.026 & 0.98 & 0.026 & 0.99 & & 0.012 & 0.99 & 0.01 \\
\hline $600-800$ & 0.96 & 0.045 & 0.95 & 0.048 & 0.96 & 0.039 & 0.97 & 0.029 & 0.97 & & 0.027 & 0.94 & 0.06 \\
\hline \multirow[t]{9}{*}{$>800$} & 0.93 & 0.075 & 0.94 & 0.059 & 0.94 & 0.063 & 0.94 & 0.06 & 0.96 & & 0.046 & 0.93 & 0.068 \\
\hline & & & & & \multicolumn{2}{|c|}{ Land } & \multicolumn{2}{|c|}{ Ocean } & & & & & \\
\hline & & & & $P(\mathrm{hPa})$ & $d \mathrm{RHi}_{q}$ & $d \mathrm{RHi}_{T}$ & $d \mathrm{RHi}_{q}$ & $d \mathrm{RHi}_{T}$ & & & & & \\
\hline & & & & $<200$ & 0.83 & 0.17 & $0.94^{4}$ & 0.066 & & & & & \\
\hline & & & & $200-400$ & 0.94 & 0.059 & 0.98 & 0.023 & & & & & \\
\hline & & & & $400-600$ & 0.96 & 0.045 & 0.98 & 0.017 & & & & & \\
\hline & & & & $600-800$ & 0.94 & 0.057 & 0.97 & 0.033 & & & & & \\
\hline & & & & $>800$ & 0.94 & 0.063 & 0.94 & 0.059 & & & & & \\
\hline & \multicolumn{2}{|c|}{ January (HIPPO1) } & \multicolumn{2}{|c|}{ Oct-Nov (HIPPO2) } & \multicolumn{2}{|c|}{ Mar-Apr (HIPPO3) } & \multicolumn{2}{|c|}{ Jun-Jul (HIPPO4) } & \multicolumn{3}{|c|}{ Aug-Sep (HIPPO5) } & \multicolumn{2}{|c|}{ April-June (START08) } \\
\hline$P(\mathrm{hPa})$ & $d \mathrm{RHi}_{q}$ & $d \mathrm{RHi}_{T}$ & $d \mathrm{RHi}_{q}$ & $d \mathrm{RHi}_{T}$ & $d \mathrm{RHi}_{q}$ & $\mathrm{RHi}_{T}$ & $d \mathrm{RHi}_{q}$ & $d \mathrm{RHi}_{T}$ & $d \mathrm{RHi}_{q}$ & $d \mathrm{R}$ & $\mathrm{Hi}_{T}$ & $d \mathrm{RHi}_{q}$ & $d \mathrm{RHi}_{T}$ \\
\hline$<200$ & 0.94 & 0.061 & 0.87 & 0.13 & 0.97 & .031 & 0.93 & 0.074 & 0.93 & 0.0 & & 0.79 & 0.21 \\
\hline $200-400$ & 0.93 & 0.069 & 0.94 & 0.062 & 0.98 & .025 & 0.97 & 0.026 & 0.96 & 0.0 & & 0.94 & 0.06 \\
\hline $400-600$ & 0.99 & 0.012 & 0.97 & 0.026 & 0.98 & .021 & 0.98 & 0.019 & 0.97 & 0.0 & & 0.95 & 0.053 \\
\hline $600-800$ & 0.98 & 0.025 & 0.96 & 0.041 & 0.97 & .029 & 0.96 & 0.037 & 0.96 & 0.0 & & 0.92 & 0.081 \\
\hline$>800$ & 0.94 & 0.064 & 0.94 & 0.061 & 0.93 & .066 & 0.94 & 0.059 & 0.94 & 0.0 & & 0.94 & 0.061 \\
\hline
\end{tabular}

The $\mathrm{O}_{3}-\mathrm{CO}$ correlation can be used to highlight stratospheric-tropospheric mixing. According to Pan et al. (2004), we define the chemical tropospheric and stratospheric regions based on the $\mathrm{O}_{3}-\mathrm{CO}$ correlations in START08. The chemical troposphere is defined by the linear fit to $\mathrm{O}_{3}<70 \mathrm{ppbv}$, i.e., $y=a+b \times x$, where $y$ is $\mathrm{O}_{3}$ (ppbv), and $x$ is CO (ppbv). Here $a$ is $47.0 \pm 0.1, b$ is $0.063 \pm 0.010$, and the standard deviation of the residuals $\left(\sigma_{y}\right)$ is 10.5. The stratospheric branch is fitted by a quadratic polynomial fit: $x=a_{0}+a_{1} y+a_{2} y^{2}$, where $y$ is $\mathrm{O}_{3}$ (ppbv), and $x$ is $\mathrm{CO}$ (ppbv). $\sigma_{x}$ is the standard deviation of the residuals. Here $a_{0}=15.0 \pm 0.2, a_{1}=0.0299 \pm 0.0005$, $a_{2}=-2.37 \times 10^{-5} \pm 3 \times 10^{-7}$, and $\sigma_{\mathrm{x}}=0.667$. Above the fit of chemical troposphere and on the right-hand side of the fit of chemical stratosphere is the extratropical transition layer (Pan et al., 2004). In Fig. 12a, the linear fit of the chemical troposphere and $\pm 3 \sigma_{y}$ of the fit are shown as the black and red dotted lines, respectively. We note that Fig. 12a is only a part of the whole $\mathrm{O}_{3}-\mathrm{CO}$ tracer plot, and therefore the fit of the chemical stratosphere is not shown in Fig. 12a. All the ISS observations in START08 happened either in the chemical troposphere or in the transition layer. The results show that most of the ISS observations (colored markers) from individual flights follow almost straight mixing lines. The extrapolations of these mixing lines can help determine the origins of air parcels being mixed. For example, the $\mathrm{O}_{3}-$ $\mathrm{CO}$ mixing lines with positive slopes represent tropospherictropospheric mixing (RF09, 16, 17 in Fig. 12a), since the extrapolations of the mixing lines intercept tropospheric air at the two ends. On the other hand, the mixing lines with negative slopes represent stratospheric-tropospheric mixing (RF11, 15 in Fig. 12a), since their extrapolations intercept stratospheric air at one end and tropospheric air at the other (such as discussed in Zahn et al., 2004).

The $\mathrm{O}_{3}-\mathrm{CO}$ correlation captures the stratospherictropospheric mixing well, but to highlight the tropospherictropospheric mixing, $\mathrm{H}_{2} \mathrm{O}_{\text {tot }}-\theta_{q}$ correlation is also analyzed here. In general, the background of the atmosphere from the surface to the UT/LS is represented as a " $C$ " shape in the $\mathrm{H}_{2} \mathrm{O}_{\text {tot }}-\theta_{q}$ correlation (i.e., the grey background in Fig. 12b). The combination of high $\mathrm{H}_{2} \mathrm{O}_{\text {tot }}$ and low $\theta_{q}$ values (upper left region) represents the tropospheric region, while the combination of low $\mathrm{H}_{2} \mathrm{O}_{\text {tot }}$ and high $\theta_{q}$ values (lower right region) represents the stratospheric region. Compared with the ISS distributions in $\mathrm{O}_{3}-\mathrm{CO}$ correlation, the ISS distributions in $\mathrm{H}_{2} \mathrm{O}_{\text {tot }}-\theta_{q}$ correlation (colored markers in Fig. 12b) follow mixing lines that deviate slightly from the straight mixing lines, which implies that the specific entropy of the air is not fully conserved. For example, if irreversible processes happen, including external inputs of sensible and/or latent heat and phase change, the mixing lines would deviate from a straight line. Based on the extrapolations of the observed mixing lines, negative and positive slopes represent tropospheric-tropospheric (RF09, 16, 17 in Fig. 12b) and stratospheric-tropospheric (RF11, 15 in Fig. 12b) mixing, respectively. 

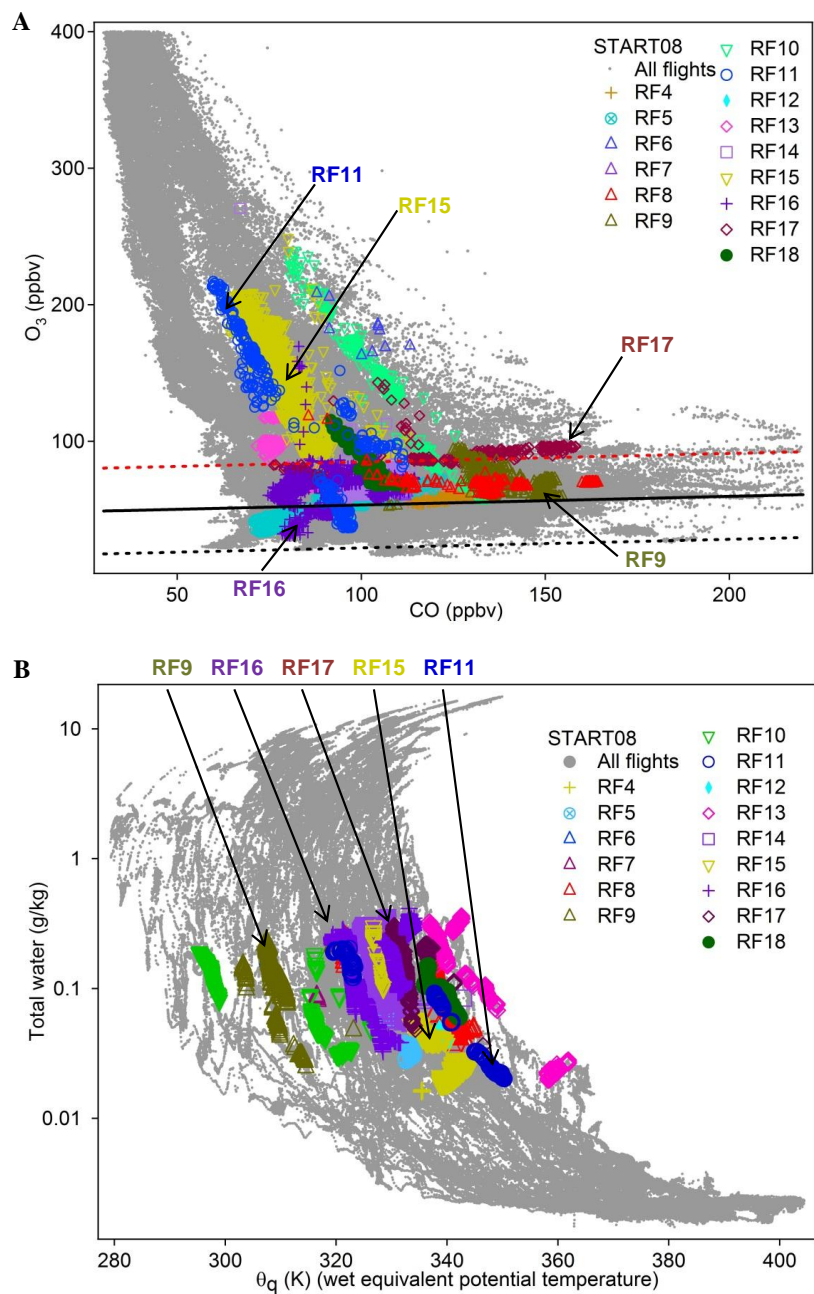

Fig. 12. ISS observations along mixing lines in conservative tracertracer correlations. (A) $\mathrm{O}_{3}-\mathrm{CO}$ correlations from START08 campaign. (B) Total water content and $\theta_{q}$ correlations in START08. The horizontal solid black line is the linear fit to the tropospheric branch of all RHi observations and dotted lines are the $\pm 3 \sigma$ of the fits. For reference, grey background points in (A) and (B) show the observations in all $T$ ranges. We note that part of the high ozone data are not shown in (A). ISS data are colored by individual flight numbers with the same markers in (A) and (B). Because the mixing lines overlap with each other in (A) and (B), we highlighted a few straight mixing lines with arrows and colored flight numbers as examples (see arrows with labels in the figure).

Most ISS mixing lines are straight, and their end points are far apart from each other, which indicates that the formation of ISS involves the mixing of two distinctively different types of air parcels (see Appendix B). This feature could be explained by the previous findings that large-scale uplift usually plays an important role in ISSR formation (Spichtinger et al., 2005a, b). The evenly distributed points along the mixing lines show that the air parcels have been well mixed on the small scale, since otherwise clusters of points would be observed at the two end points. This result is consistent with the previous simulation, which shows that small-scale turbulence and eddies can play important roles in triggering ISS formation and the subsequent ice freezing events (Fusina and Spichtinger, 2010). Thus, both large- and small-scale processes play important roles in setting the environment of ISSR formation. On the one hand, uplifting and cooling provide the environments for ISSR formation on the mesoscale, and these contribute to the increase of RHi in the Lagrangian view (Spichtinger et al., 2005a, b). On the other hand, smallscale processes contribute to the microscale structure of ISSRs. For example, one possible cause of the microscale $\mathrm{H}_{2} \mathrm{O}$ spatial variability might be the widely observed turbulence in the troposphere (Gage and Nastrom, 1986; Nastrom and Gage, 1985; Nastrom et al., 1986). Yet we caution that highresolution measurements of 3-D wind fields are needed to fully understand the cause of the microscale spatial variability of $\mathrm{H}_{2} \mathrm{O}$ field in the future.

\subsection{Eulerian view examples of using $\mathrm{H}_{2} \mathrm{O}$ and $T$ variabilities to derive RHi variabilities}

Here we use one example to demonstrate that the importance of $\mathrm{H}_{2} \mathrm{O}$ horizontal variabilities when deriving the RHi horizontal variabilities in the Eulerian view (Fig. 13). Fig. 13a shows a typical time series of RHi (black solid line), $T$ (purple cross) and $\mathrm{H}_{2} \mathrm{O}$ (light-blue dashed line) during a flight. The grey areas in Fig. 13a and c represent the ISSRs. If one only uses $T$ spatial fluctuations in the Eulerian view to derive RHi spatial variability and neglects the $\mathrm{H}_{2} \mathrm{O}$ spatial fluctuations (Fig. 13b red short dashed line), the generated ISS occurrences would be much lower compared with those in real observations (Fig. 13a). In addition, if one uses $T$ fluctuations to compensate for the neglected $\mathrm{H}_{2} \mathrm{O}$ fluctuations (Fig. 13c pink dashed line), even though the RHi field is the same, the generated $T$ in ISSRs would be much lower unnecessarily (by up to $\sim 2 \mathrm{~K}$ in this example, Fig. 13c) than the observed $T$ in ISSRs (Fig. 13a). We note that for this example, the uncertainty in RHi is $\sim 13 \%$. Yet regardless of the uncertainties in $\mathrm{RHi}$, the contribution of $\mathrm{H}_{2} \mathrm{O}$ variability to the variability of RHi would still be dominant even if all RHi values in this time series are lowered or increased by $13 \%$ altogether. The artificially lower $T$ inside the ISSRs in this case will lead to unrealistic conditions for ice nucleation, given the sensitivities of ice crystal growth rate and small-scale turbulences to the $T$ field. Thus it is critical that the spatial variabilities of $\mathrm{H}_{2} \mathrm{O}$ are considered instead of being neglected or compensated for by $T$ spatial variabilities. The extent of $\mathrm{H}_{2} \mathrm{O}$ horizontal variabilities may be a useful observational constraint to compare the 4-D cloud microphysics models with 1-D aircraft observations. 

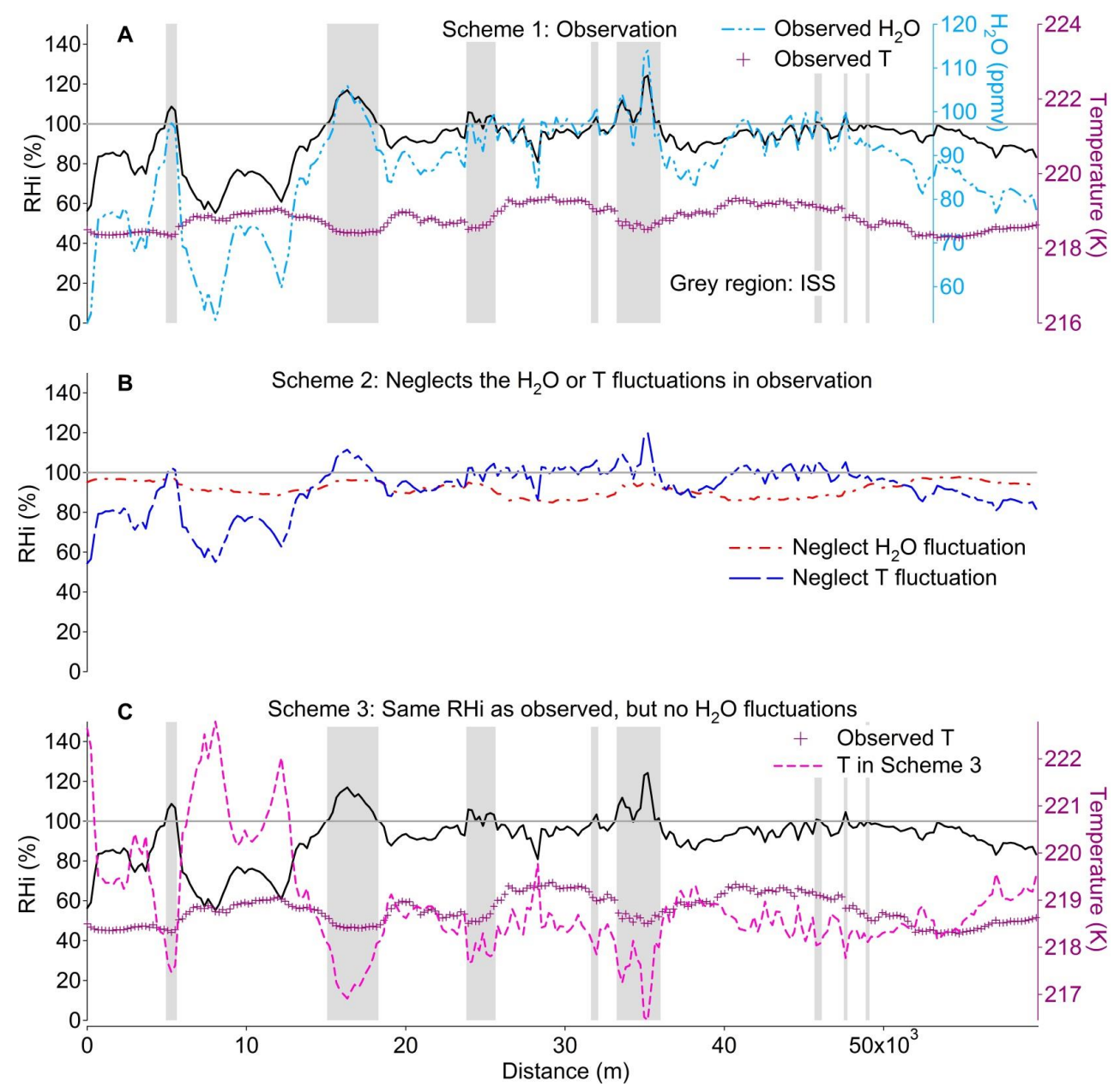

Fig. 13. Example of derivations of ISS spatial variability on a horizontal layer. The horizontal grey solid line denotes $\mathrm{RHi}=100 \%$ and grey regions in (A) and (C) represent ISSRs. (A) Scheme 1 is an example of the horizontal distribution of RHi (black line), $T$ (purple cross) and $\mathrm{H}_{2} \mathrm{O}$ (light-blue dashed line) from the observation. (B) Scheme 2 either neglects $\mathrm{H}_{2} \mathrm{O}$ variability or $T$ variability from the observation. The red short dashed line (blue long dashed line) uses the same $T\left(\mathrm{H}_{2} \mathrm{O}\right)$ variability as observed, but neglects $\mathrm{H}_{2} \mathrm{O}(T)$ fluctuations and only considers the mean $\mathrm{H}_{2} \mathrm{O}(T)$ value. The result gives no ISS when neglecting $\mathrm{H}_{2} \mathrm{O}$ fluctuations. (C) Scheme 3 uses $T$ fluctuations to generate the same RHi distribution as observed, but still neglects $\mathrm{H}_{2} \mathrm{O}$ fluctuations. The result implies lower $T$ values in ISSRs (pink dashed line) than the observed $T$ values (purple cross).

\section{Atmospheric implications and future work}

The formation of the microscale ISSRs are likely attributed to many dynamical processes on various scales. For example, on the microscale, processes such as small-scale turbulence, small gravity waves, entrainment mixing and ice crystal sedimentation could generate the microscale spatial variability of $\mathrm{H}_{2} \mathrm{O}$, which defines the location and magnitude of microscale ISSRs in the horizontal Eulerian view. On the other hand, mesoscale processes such as uplifting, largescale gravity waves and deep convection could contribute to the overall environment of cooling, which lower $T$ and increase RH in the Lagrangian view. Future work is needed on both scales in order to quantify the contribution of individual processes to the formation of ISSRs. For example, back- trajectory analyses are needed to assess the roles of largescale dynamics in setting the overall cooling environment, while tracer analyses are needed to assess the roles of turbulence and mixing between air masses in contributing to the heterogeneities of the $\mathrm{H}_{2} \mathrm{O}$ field. In particular, specific case studies will be helpful in order to quantify the scales of vertical displacements that can generate the observed $\mathrm{H}_{2} \mathrm{O}$ variability based on a local $\mathrm{H}_{2} \mathrm{O}$ profile.

Our results show that although the dynamic causes of $\mathrm{H}_{2} \mathrm{O}$ variabilities may differ, the strong correlation between RHi and $\mathrm{H}_{2} \mathrm{O}$ horizontal variabilities holds at each horizontal layer from the surface to the extratropical UT/LS and tropical $\mathrm{UT}$, from $87^{\circ} \mathrm{N}$ to $67^{\circ} \mathrm{S}$, and is applicable for all cloud scales $(\sim 0.23-115 \mathrm{~km})$. This ubiquitously observed feature provides a unique validation method for cloud and climate 
models on ISS spatial variability. In particular, there are currently various small-scale dynamics considered in the cloud models (Jensen and Pfister, 2004; Spichtinger and Krämer, 2013), as well as various parameterization schemes used to generate ISS sub-grid variability in the climate models (Kärcher and Burkhardt, 2008; Wang and Penner, 2010). Recent results from some cirrus cloud models have shown that including the ISS generated by small-scale dynamical processes can have large impacts on cloud microphysics and ice crystal properties (Jensen and Pfister, 2004; Spichtinger and Krämer, 2013). Climate models also showed that the inclusion of sub-grid-scale ISS variability can modify the cloud radiative forcing on the atmosphere (Kärcher and Burkhardt, 2008; Wang and Penner, 2010). In fact, most cloud models (Jensen and Pfister, 2004; Jensen, 2005) and climate models (Kärcher and Burkhardt, 2008; Wang and Penner, 2010) have been using $T$ variability as one of the main constraints for ISS variability, because not only is it commonly accepted that the decrease of $T$ drives the increase of RHi in a massconservative Lagrangian view but it is also known that the mesoscale $(\sim 100 \mathrm{~km}) T$ fluctuations have been widely observed in the UT/LS (Gary, 2006). Future work is needed to compare the simulation results with the observations on the contribution of $\mathrm{H}_{2} \mathrm{O}$ spatial variability to RHi spatial variability in each horizontal layer. Understanding how the spatial $\mathrm{H}_{2} \mathrm{O}$ variability comes about, and why it is such a dominant factor in the Eulerian view RHi field, will require future modeling studies and ultimately more accurate cloud models.

\section{Appendix A}

\section{Calculation of wet equivalent potential temperature $\left(\theta_{q}\right)$}

We here show the derivation of $\theta_{q}$ that has been used in our analyses. At $T \leq-40^{\circ} \mathrm{C}$, air parcels contain dry air, water vapor and ice particles with no supercooled liquid water (Murphy and Koop, 2005). The entropy of air can be expressed as

$s=s_{\mathrm{d}}+q s_{v}+r_{\text {ice }} s_{\text {ice }}$,

where $s_{\mathrm{d}}, s_{\mathrm{V}}$ and $s_{\text {ice }}$ are the specific entropy of dry air, water vapor and ice, respectively, and $q$ and $r_{\text {ice }}$ are the mass mixing ratios of water vapor and ice $\left(\mathrm{kg} \mathrm{kg}^{-1}\right)$, respectively.

$s_{\mathrm{d}}=C_{\mathrm{pd}} \ln T-R_{\mathrm{d}} \ln P_{\mathrm{d}}$,

$s_{\mathrm{v}}=C_{\mathrm{pv}} \ln T-R_{\mathrm{v}} \ln e$,

$s_{\text {ice }}=C_{\text {ice }} \ln T$,

where $R_{\mathrm{d}}\left(287 \mathrm{~J} \mathrm{~kg}^{-1} \mathrm{~K}^{-1}\right)$ and $R_{\mathrm{V}}\left(461 \mathrm{~J} \mathrm{~kg}^{-1} \mathrm{~K}^{-1}\right)$ are the gas constants for dry air and water vapor, respectively (Emanuel, 1994); $P_{\mathrm{d}}$ and $e$ are dry air and water vapor partial pressures $(P a)$, respectively. $C_{\mathrm{pd}}\left(1004 \mathrm{~J} \mathrm{~kg}^{-1} \mathrm{~K}^{-1}\right)$, $C_{\mathrm{pv}}\left(1870 \mathrm{~J} \mathrm{~kg}^{-1} \mathrm{~K}^{-1}\right)$ and $C_{\text {ice }}\left(\mathrm{J} \mathrm{kg}^{-1} \mathrm{~K}^{-1}\right)$ are the specific heats of dry air at constant pressure, water vapor at constant pressure and ice, respectively (Emanuel, 1994); and $C_{\text {ice }}$ is calculated based on the value of molecular heat capacity of ice $\left(C_{\mathrm{p}, \text { ice }}\right)$. Here the calculation of $C_{\mathrm{p} \text {,ice }}$ at $T>20 \mathrm{~K}$ is shown as below (Emanuel, 1994; Giauque and Stout, 1936):

$C_{\mathrm{p}, \text { ice }}=-2.0572+0.14644 T+0.06163 T \exp \left(-\left(\frac{T}{125.1}\right)^{2}\right)$,

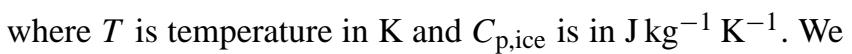
use $T=-51.8^{\circ} \mathrm{C}$ (mean temperature in START08) and get $C_{\mathrm{p}, \text { ice }}=31.0 \mathrm{~J} \mathrm{~mol}^{-1} \mathrm{~K}^{-1}$; thus $C_{\text {ice }}=1.75 \times 10^{3} \mathrm{~J} \mathrm{~kg}^{-1} \mathrm{~K}^{-1}$.

Based on the definition of wet equivalent potential temperature $\left(\theta_{q}\right)$ in Eq. (4.5.11) of Emanuel (1994) for warm clouds (mixture of liquid water droplets, water vapor and dry air), we derive our $\theta_{q}$ for cold clouds (mixture of ice particles, water vapor and dry air at $T \leq-40^{\circ} \mathrm{C}$ ). Our calculation of $\theta_{q}$ is shown as below and it applies to the entire RHi range from subsaturation to supersaturation:

$\theta_{q}=T\left(\frac{p_{0}}{p_{\mathrm{d}}}\right)^{\frac{R_{\mathrm{d}}}{C_{\mathrm{pd}}+Q C_{\mathrm{ice}}}}\left(\frac{R H i}{100}\right)^{-\frac{q R_{\mathrm{v}}}{C_{\mathrm{pd}}+Q C_{\text {ice }}}} \exp \left(\frac{L_{\mathrm{ice}} q}{\left(C_{\mathrm{pd}}+Q C_{\text {ice }}\right) T}\right)$,

where $P_{0}$ is the reference pressure of $1000 \mathrm{mb}$, the total water content $Q$ is defined as $Q=q+r_{\text {ice }}$, and $L_{\text {ice }}$ is the latent heat of sublimation. The function of $L_{\text {ice }}$ for $T>30 \mathrm{~K}$ is as below (Murphy and Koop, 2005):

$L_{\text {ice }}=46782.5+35.8925 T-0.07414 T^{2}+541.5 \exp \left(-\left(\frac{T}{123.75}\right)^{2}\right)$,

where $T$ is temperature in $\mathrm{K}$. We use $T=-51.8^{\circ} \mathrm{C}$ (mean temperature in START08) and get $L_{\text {ice }}=5.11 \times 10^{4} \mathrm{~J} \mathrm{~mol}^{-1} \mathrm{~K}^{-1}$; thus $L_{\text {ice }}=2.84 \times 10^{6} \mathrm{~J} \mathrm{~kg}^{-1} \mathrm{~K}^{-1}$. Equation (A6) applies for all conditions: subsaturation, saturation and supersaturation as well as both clear-sky and in-cloud conditions.

\section{Appendix B}

\section{Mixing line mechanism}

Chemical tracers inside the parcels can be considered to be conservative tracers if they have much longer lifetimes than the mixing timescale. For example, $\mathrm{O}_{3}$ and $\mathrm{CO}$ can be used as tracers of tropospheric and stratospheric air, respectively. If the research aircraft samples through a region that contains air parcels from very different origins, this mixing feature will show up in the tracer-tracer correlation plot as a curve or line, which means that the concentrations of conservative properties show variations along the sampling transect. If there is no mixing process, the correlation plot should show almost the same values throughout. Whether the mixing feature will appear as a curve or a straight line in the correlation plots is determined by the number of different levels of air that are mixed altogether. The straight line represents mixing of air parcels only from two levels, while the curve represents mixing of air from more than two levels (Paluch, 
1979). In the case of mixing of two levels, we use $X$ and $Y$ to represent the two conservative properties, and subscripts 1 and 2 to represent two air parcels. The conserved properties after mixing $\left(X^{\prime}\right.$ and $\left.Y^{\prime}\right)$ can be calculated as

$X^{\prime}=f_{1} X_{1}+f_{2} X_{2}$,

$Y^{\prime}=f_{1} Y_{1}+f_{2} Y_{2}$,

where $f_{1}$ and $f_{2}$ are the fractions of a unit mass of the final mixture constituted by fluid originally contained by parcel 1 and 2, respectively. By mass conservation, $f_{1}+f_{2}=1$. The ratio of the two conserved properties $X$ and $Y$ after mixing follows a certain relationship as below:

$Y^{\prime}=X^{\prime} \frac{Y_{2}-Y_{1}}{X_{2}-X_{1}}+Y_{1}-\frac{X_{1}\left(Y_{2}-Y_{1}\right)}{X_{2}-X_{1}}$.

The correlation of $Y(X)$ has a constant slope, $\frac{Y_{2}-Y_{1}}{X_{2}-X_{1}}$, which is only defined by the initial values of $X_{1}, X_{2}, Y_{1}$ and $Y_{2}$. The intercept of the correlation is $Y_{1}-\frac{X_{1}\left(Y_{2}-Y_{1}\right)}{X_{2}-X_{1}}$, which is also a constant. The values of the conservative properties along the straight mixing line are bounded by the original values at the two levels. Therefore, by extrapolating the mixing lines the origins of the mixed air can be coarsely estimated (Paluch, 1979; Pan et al., 2004).

To demonstrate that the mixing between more than two levels would not follow a straight line, we show the example of three-level mixing. Here $X$ and $Y$ still represent the two conservative properties and subscripts 1, 2 and 3 represent three air parcels, and thus the conserved properties after mixing $\left(X^{\prime}\right.$ and $\left.Y^{\prime}\right)$ can be calculated as

$X^{\prime}=f_{1} X_{1}+f_{2} X_{2}+f_{3} X_{3}$,

$Y^{\prime}=f_{1} Y_{1}+f_{2} Y_{2}+f_{3} Y_{3}$,

where $f_{1}, f_{2}$ and $f_{3}$ are the fractions of a unit mass of the final mixture constituted by fluid originally contained by parcels 1,2 and 3, respectively. By mass conservation, $f_{1}+f_{2}+f_{3}=1$. In this case there are five variables $(X$, $Y, f_{1}, f_{2}$ and $\left.f_{3}\right)$ in three equations. Therefore $Y$ is not only a function of $X$ but also depends on the ratio of the mixing. The function of $Y\left(X, f_{3}\right)$ is shown as below (similar functions can be derived for $Y\left(X, f_{1}\right)$ and $\left.Y\left(X, f_{2}\right)\right)$ :

$Y^{\prime}=X^{\prime} \frac{Y_{2}-Y_{1}}{X_{2}-X_{1}}+f_{3}\left(Y_{3}-Y_{1}-\frac{\left(Y_{2}-Y_{1}\right)\left(X_{3}-X_{1}\right)}{\left(X_{2}-X_{1}\right)}\right)$

$+Y_{1}-\frac{X_{1}\left(Y_{2}-Y_{1}\right)}{X_{2}-X_{1}}$

The $Y\left(X, f_{3}\right)$ correlation function will not follow a straight line in the correlation plot since it is highly unlikely that $f_{3}$ (or $f_{1}, f_{2}$ ) will be constant within the mixing region as the mixing inside the region is not strictly uniform everywhere.
Acknowledgements. We gratefully acknowledge funding for field support and data analyses from the following sources: NSF ATM-0840732 (HIPPO Global campaign) and AGS-1036275 (START08 campaign) for VCSEL (Princeton). M. Diao gratefully acknowledges support from the NASA Earth and Space Science Graduate Fellowship (NASA NNX09AO51H) and the Walbridge Fund Graduate Award. We appreciate the efforts of NCAR EOL flight, technical, and mechanical crews during START08 and HIPPO Global, in particular P. Romashkin for field maintenance of the VCSEL hygrometer. We also appreciate helpful discussions with L. Donner, S. Fueglistaler, L. L. Pan and I. M. Held. Comments and suggestions from two anonymous reviewers are also appreciated.

Edited by: D. J. Cziczo

\section{References}

Cho, J. Y. N., Newell, R. E., and Sachse, G. W.: Anomalous scaling of mesoscale tropospheric humidity fluctuations, Geophys. Res. Lett., 27, 377-380, doi:10.1029/1999GL010846, 2000.

Cotton, R., Osborne, S., Ulanowski, Z., Hirst, E., Kaye, P. H., and Greenaway, R. S.: The Ability of the Small Ice Detector (SID-2) to Characterize Cloud Particle and Aerosol Morphologies Obtained during Flights of the FAAM BAe-146 Research Aircraft, J. Atmos. Ocean. Technol., 27, 290-303, doi:10.1175/2009JTECHA1282.1, 2010.

Cziczo, D. J., Froyd, K. D., Hoose, C., Jensen, E. J., Diao, M., Zondlo, M. A., Smith, J. B., Twohy, C. H., and Murphy, D. M.: Clarifying the Dominant Sources and Mechanisms of Cirrus Cloud Formation, Science, 340, 1320-1324, doi:10.1126/science.1234145, 2013.

Davis, S. M., Hallar, A. G., Avallone, L. M., and Engblom, W.: Measurement of total water with a tunable diode laser hygrometer: Inlet analysis, calibration procedure, and ice water content determination, J. Atmos. Ocean. Technol., 24, 463-475, doi:10.1175/JTECH1975.1, 2007.

Diao, M., Zondlo, M. A., Heymsfield, A. J., Beaton, S. P., and Rogers, D. C.: Evolution of ice crystal regions on the microscale based on in situ observations, Geophys. Res. Lett., 40, 34733478, doi:10.1002/grl.50665, 2013.

Dickson, N. C., Gierens, K. M., Rogers, H. L., and Jones, R. L.: Probabilistic description of ice-supersaturated layers in low resolution profiles of relative humidity, Atmos. Chem. Phys., 10, 6749-6763, doi:10.5194/acp-10-6749-2010, 2010.

Emanuel, K. A.: Atmospheric Convection, Oxford University Press, 107-144, 1994.

Fusina, F. and Spichtinger, P.: Cirrus clouds triggered by radiation, a multiscale phenomenon, Atmos. Chem. Phys., 10, 5179-5190, doi:10.5194/acp-10-5179-2010, 2010.

Gage, K. S. and Nastrom, G. D.: Theoretical Interpretation of Atmospheric Wavenumber Spectra of Wind and Temperature Observed by Commercial Aircraft During GASP, J. Atmos. Sci., 43, 729-740, doi:10.1175/15200469(1986)043<0729:TIOAWS>2.0.CO;2, 1986.

Gary, B. L.: Mesoscale temperature fluctuations in the stratosphere, Atmos. Chem. Phys., 6, 4577-4589, doi:10.5194/acp-6-45772006, 2006. 
Gettelman, A., Fetzer, E. J., Eldering, A. and Irion, F. W.: The Global Distribution of Supersaturation in the Upper Troposphere from the Atmospheric Infrared Sounder, J. Clim., 19, 6089-6103, doi:10.1175/JCLI3955.1, 2006.

Giauque, W. F. and Stout, J. W.: The entropy of water and the third law of thermodynamics. The heat capacity of ice from 15 to 274 ${ }^{\circ} \mathrm{K}, \mathrm{J}$. Am. Chem. Soc., 58, 1144-1150, 1936.

Gierens, K. and Spichtinger, P.: On the size distribution of ice-supersaturated regions in the upper troposphere and lowermost stratosphere, Annales Geophysicae, 18, 499-504, doi:10.1007/s00585-000-0499-7, 2000.

Gierens, K., Kohlhepp, R., Dotzek, N., and Smit, H. G.: Instantaneous fluctuations of temperature and moisture in the upper troposphere and tropopause region. Part 1: Probability densities and their variability, Meteorol. Zeitschr., 16, 221-231, doi:10.1127/0941-2948/2007/0197, 2007.

Heymsfield, A. J., Miloshevich, L. M., Twohy, C., Sachse, G., and Oltmans, S.: Upper-tropospheric relative humidity observations and implications for cirrus ice nucleation, Geophys. Res. Lett., 25, 1343, doi:10.1029/98GL01089, 1998.

Jensen, E. J.: Formation of a tropopause cirrus layer observed over Florida during CRYSTAL-FACE, J. Geophys. Res., 110, D03208, doi:10.1029/2004JD004671, 2005.

Jensen, E. J. and Pfister, L.: Transport and freeze-drying in the tropical tropopause layer, J. Geophys. Res., 109, D02207, doi:10.1029/2003JD004022, 2004.

Kahn, B. H. and Teixeira, J.: A Global Climatology of Temperature and Water Vapor Variance Scaling from the Atmospheric Infrared Sounder, J. Clim., 22, 5558-5576, doi:10.1175/2009JCLI2934.1, 2009.

Kahn, B. H., Gettelman, A., Fetzer, E. J., Eldering, A., and Liang, C. K.: Cloudy and clear-sky relative humidity in the upper troposphere observed by the A-train, J. Geophys. Res., 114, D00H02, doi:10.1029/2009JD011738, 2009.

Kahn, B. H., Teixeira, J., Fetzer, E. J., Gettelman, A., HristovaVeleva, S. M., Huang, X., Kochanski, A. K., Köhler, M., Krueger, S. K., Wood, R., and Zhao, M.: Temperature and Water Vapor Variance Scaling in Global Models: Comparisons to Satellite and Aircraft Data, J. Atmos. Sci., 68, 2156-2168, doi:10.1175/2011JAS3737.1, 2011.

Kärcher, B. and Burkhardt, U.: A cirrus cloud scheme for general circulation models, Quarterly J. Roy. Meteorol. Soc., 134, 1439_ 1461, doi:10.1002/qj.301, 2008.

Kärcher, B and Spichtinger, P.: Clouds in the Perturbed Climate System: Their Relationship to Energy Balance, Atmospheric Dynamics, and Precipitation, edited by J. Heintzenberg and J. R. Charlson, MIT Press, Cambridge, Mass., 235-267, 2009.

Koop, T., Luo, B., Tsias, A., and Peter, T.: Water activity as the determinant for homogeneous ice nucleation in aqueous solutions, Nature, 406, 611-461, doi:10.1038/35020537, 2000.

Korolev, A. V., Emery, E. F., Strapp, J. W., Cober, S. G., Isaac, G. A., Wasey, M., and Marcotte, D.: Small Ice Particles in Tropospheric Clouds: Fact or Artifact? Airborne Icing Instrumentation Evaluation Experiment, B. Am. Meteorol. Soc., 92, 967-973, doi:10.1175/2010BAMS3141.1, 2011.

Krämer, M., Schiller, C., Afchine, A., Bauer, R., Gensch, I., Mangold, A., Schlicht, S., Spelten, N., Sitnikov, N., Borrmann, S., de Reus, M., and Spichtinger, P.: Ice supersaturations and cir- rus cloud crystal numbers, Atmos. Chem. Phys., 9, 3505-3522, doi:10.5194/acp-9-3505-2009, 2009.

Lamquin, N., Stubenrauch, C. J., Gierens, K., Burkhardt, U., and Smit, H.: A global climatology of upper-tropospheric ice supersaturation occurrence inferred from the Atmospheric Infrared Sounder calibrated by MOZAIC, Atmos. Chem. Phys., 12, 381405, doi:10.5194/acp-12-381-2012, 2012.

Liou, K. N.: Radiation and cloud processes in the atmosphere, Oxford University Press, 255-339, 1992.

Lynch, D. K., Sassen, K., Starr, D. C., and Stephens, G.: Cirrus, edited by D. K. Lynch, K. Sassen, D. C. Starr, and G. Stephens, Oxford Univ. Press, New York, 375-432, 2002.

Murphy, D. M. and Koop, T.: Review of the vapour pressures of ice and supercooled water for atmospheric applications, Q. J. Roy. Meteorol. Soc., 131(608), 1539-1565, doi:10.1256/qj.04.94, 2005.

Nastrom, G. D. and Gage, K. S.: A Climatology of Atmospheric Wavenumber Spectra of Wind and Temperature Observed by Commercial Aircraft, J. Atmos. Sci., 42(9), 950-960, doi:10.1175/1520-0469(1985)042<0950:ACOAWS>2.0.CO;2, 1985.

Nastrom, G. D., Jasperson, W. H., and Gage, K. S.: Horizontal spectra of atmospheric tracers measured during the Global Atmospheric Sampling Program, J. Geophys. Res., 91, 13201-13209, doi:10.1029/JD091iD12p13201, 1986.

Ovarlez, J., Gayet, J. F., Gierens, K., Strom, J., Ovarlez, H., Auriol, F., Busen, R., and Schumann, U.: Water vapour measurements inside cirrus clouds in Northern and Southern hemispheres during INCA, Geophys. Res. Lett., 29, 1813, doi:10.1029/2001GL014440, 2002.

Paluch, I. R.: The Entrainment Mechanism in Colorado Cumuli, J. Atmos. Sci., 36, 2467-2478, 1979.

Pan, L. L., Randel, W. J., Gary, B. L., Mahoney, M. J., and Hintsa, E. J.: Definitions and sharpness of the extratropical tropopause: A trace gas perspective, J. Geophys. Res., 109, D23103, doi:10.1029/2004JD004982, 2004.

Pan, L. L., Bowman, K. P., Atlas, E. L., Wofsy, S. C., Zhang, F., Bresch, J. F., Ridley, B. A., Pittman, J. V., Homeyer, C. R., Romashkin, P. and Cooper, W. A.: The Stratosphere-Troposphere Analyses of Regional Transport 2008 Experiment, B. Am. Meteorol. Soc., 91, 327-342, doi:10.1175/2009BAMS2865.1, 2010.

Peter, T., Marcolli, C., Spichtinger, P., Corti, T., Baker, M. B. and Koop, T.: When dry air is too humid., Science, 314, 1399-1402, doi:10.1126/science.1135199, 2006.

Price, J. D. and Wood, R.: Comparison of probability density functions for total specific humidity and saturation deficit humidity,and consequences for cloud parametrization, Q. J. Roy. Meteorol. Soc., 128, 2059-2072, doi:10.1256/003590002320603539, 2002.

Solomon, S., Qin, D., Manning, M., Chen, Z., Marquis, M., Avery, K. B., Tignor, M., and Miller, H. L.: Climate Change 2007: The Physical Science Basis, edited by: Solomon, S., Qin, D., Manning, M., Chen, Z., Marquis, M., Avery, K. B., Tignor, M., and Miller, H. L., Cambridge University Press, 2007.

Spichtinger, P. and Krämer, M.: Tropical tropopause ice clouds: a dynamic approach to the mystery of low crystal numbers, Atmos. Chem. Phys., 13, 9801-9818, doi:10.5194/acp-13-98012013, 2013. 
Spichtinger, P., Gierens, K., and Read, W.: The global distribution of ice-supersaturated regions as seen by the Microwave Limb Sounder, Q. J. Roy. Meteorol. Soc., 129, 3391-3410, doi:10.1256/qj.02.141, 2003.

Spichtinger, P., Gierens, K., and Dörnbrack, A.: Formation of ice supersaturation by mesoscale gravity waves, Atmos. Chem. Phys., 5, 1243-1255, doi:10.5194/acp-5-1243-2005, 2005a.

Spichtinger, P., Gierens, K., and Wernli, H.: A case study on the formation and evolution of ice supersaturation in the vicinity of a warm conveyor belt's outflow region, Atmos. Chem. Phys., 5, 973-987, doi:10.5194/acp-5-973-2005, 2005b.

Tilmes, S., Pan, L. L., Hoor, P., Atlas, E., Avery, M. A., Campos, T., Christensen, L. E., Diskin, G. S., Gao, R. S., Herman, R. L., Hintsa, E. J., Loewenstein, M., Lopez, J., Paige, M. E., Pittman, J. V, Podolske, J. R., Proffitt, M. R., Sachse, G. W., Schiller, C., Schlager, H., Smith, J., Spelten, N., Webster, C., Weinheimer, A., and Zondlo, M. A.: An aircraft-based upper troposphere lower stratosphere $\mathrm{O} 3, \mathrm{CO}$, and $\mathrm{H} 2 \mathrm{O}$ climatology for the Northern Hemisphere, J. Geophys. Res., 115, D14303, doi:10.1029/2009JD012731, 2010.

Vömel, H., Oltmans, S. J., Johnson, B. J., Hasebe, F., Shiotani, M., Fujiwara, M., Nishi, N., Agama, M., Cornejo, J., Paredes, F., and Enriquez, H.: Balloon-borne observations of water vapor and ozone in the tropical upper troposphere and lower stratosphere, J. Geophys. Res., 107, ACL 8-1-ACL 8-16, doi:10.1029/2001JD000707, 2002.

Wang, M. and Penner, J. E.: Cirrus clouds in a global climate model with a statistical cirrus cloud scheme, Atmos. Chem. Phys., 10, 5449-5474, doi:10.5194/acp-10-5449-2010, 2010.
Wofsy, S. C., Daube, B. C., Jimenez, R., Kort, E., Pittman, J. V., Park, S., Commane, R., Xiang, B., G.Santoni, Jacob, D., Fisher, J., Pickett-Heaps, C., Wang, H., Wecht, K., Wang, Q.Q., Stephens, B. B., Schertz, S., Romashkin, P., Campos, T., Haggerty, J., Cooper, W. A., Rogers, D., Beaton, S., Elkins, J. W., Fahey, D., Gao, R., Moore, F., Montzka, S. A., Schwartz, J. P., Hurst, D., Miller, B., Sweeney, C., Oltmans, S., Nance, D., Hintsa, E. F., Dutton, G., Watts, L. A., Spackman, R., Rosenlof, K., Ray, E., Zondlo, M. A., Diao, M., Mahoney, M. J., Chahine, M. T., Olsen, E., Keeling, R., Bent, J., Atlas, E. A., Lueb, R., Patra, P., Ishijima, K., Engelen, R., Nassar, R., Jones, D. B. and Mikaloff-Fletcher., S.: HIAPER Pole-to-Pole Observations (HIPPO): fine-grained, global-scale measurements of climatically important atmospheric gases and aerosols., Phil. Trans. Roy. Soc. A Math Phys. Eng. Sci., 369, 2073-2086, doi:10.1098/rsta.2010.0313, 2011.

Wood, R. and Field, P. R.: The Distribution of Cloud Horizontal Sizes, J. Clim., 24, 4800-4816, doi:10.1175/2011JCLI4056.1, 2011.

Wylie, D. P. and Menzel, W. P.: Eight Years of High Cloud Statistics Using HIRS, J. Clim., 12, 170-184, doi:10.1175/1520-044212.1.170, 1999.

Zahn, A., Brenninkmeijer, C. A. M. and Velthoven, P. F. J. van: Passenger aircraft project CARIBIC 1997-2002, Part I: The extratropical chemical tropopause, Atmos. Chem. Phys. Discuss., 4, 1091-1117, 2004, http://www.atmos-chem-phys-discuss.net/4/1091/2004/.

Zondlo, M. A., Paige, M. E., Massick, S. M. and Silver, J. A.: Vertical cavity laser hygrometer for the National Science Foundation Gulfstream-V aircraft, J. Geophys. Res., 115, D20309, doi:10.1029/2010JD014445, 2010. 